Western (Aechmophorus occidentalis)

Fish a Wildife Division

RESOURBESTATUS AND ASSESSMENT BRANOH and Eared (Podiceps nigricollis)

Grebes of Central Alberta:

Inventory, Survey Techniques, and Management Concerns

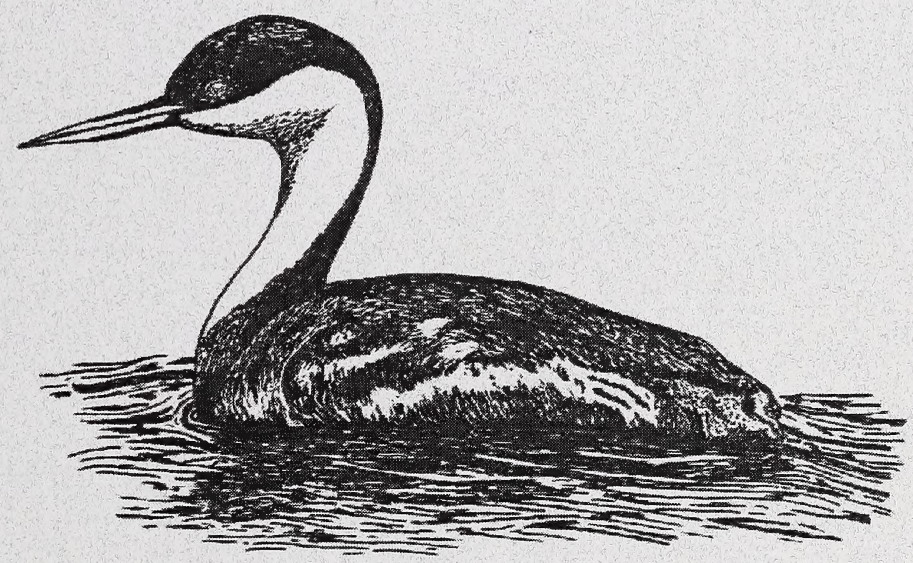

Alberta Species at Risk Report No. 41 
Digitized by the Internet Archive in 2016

https://archive.org/details/westernaechmopho00hanu_1 


\title{
Western (Aechmophorus occidentalis) and Eared (Podiceps nigricollis) Grebes of Central Alberta: Inventory, Survey Techniques, and Management Concerns
}

\author{
Stephen Hanus \\ Hugh Wollis \\ and \\ Lisa Wilkinson
}

Alberta Species at Risk Report No. 41

March 2002

Project Partners:

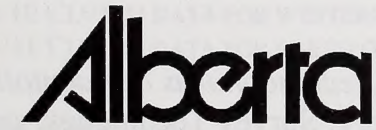

SUSTAINABLE RESOURCE DEVELOPMENT
North American Waterfowl Management Plan Plan nord-americain de gestion de la sauvagine

Plan de Manejo do Aves Acuaticas de Norteamerica 
Publication No.: I/058

ISBN: 0-7785-2012-9 (Printed Edition)

ISBN: 0-7785-2013-7 (On-line Edition)

ISSN: 1496-7219 (Printed Edition)

ISSN: 1496-7146 (On-line Edition)

Illustration: Stephen Hanus

For copies of this report, contact:

Information Centre - Publications

Alberta Environment / Alberta Sustainable Resource Development

Main Floor, Great West Life Building

9920108 Street

Edmonton, Alberta, Canada T5K 2M4

Telephone (780) 422-2079

\section{OR}

Information Service

Alberta Environment / Alberta Sustainable Resource Development \#100, 311512 Street NE

Calgary, Alberta, Canada T2E 7J2

Telephone (403) 297-3362

\section{OR}

Visit our website at:

http://www3.gov.ab.ca/srd/fw/riskspecies/

This publication may be cited as:

Hanus, S., H. Wollis, and L. Wilkinson. 2002. Western (Aechmophorus occidentalis) and Eared (Podiceps nigricollis) Grebes of Central Alberta: Inventory, Survey Techniques, and Management Concerns. Alberta Sustainable Resource Development, Fish and Wildlife Division, Species at Risk Report No. 41. Edmonton, AB. 


\section{TABLE OF CONTENTS}

ACKNOWLEDGEMENTS V

EXECUTIVE SUMMARY vi

1.0 INTRODUCTION 1

2.0 STUDY AREA 2

3.0 METHODS 3

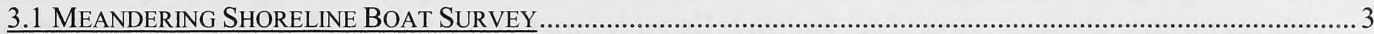

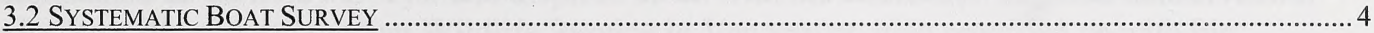

3.3 AIR SURVEY

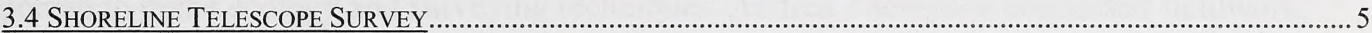

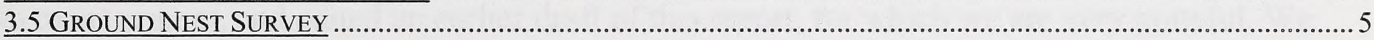

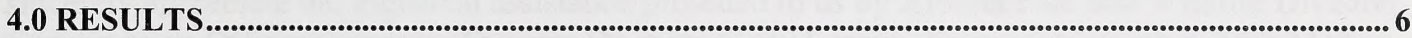

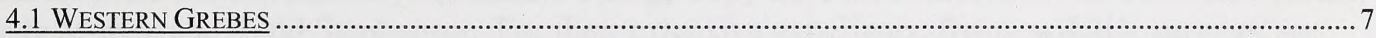

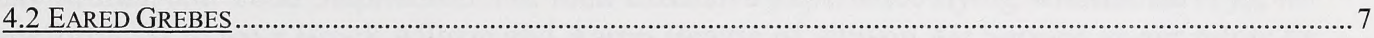

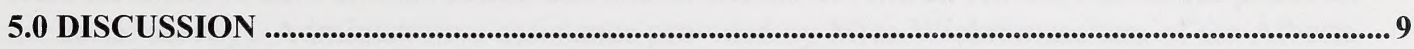

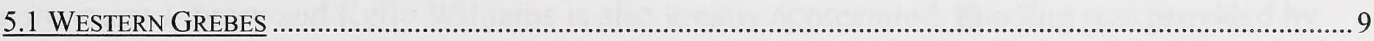

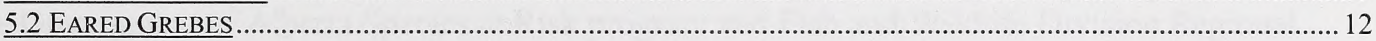

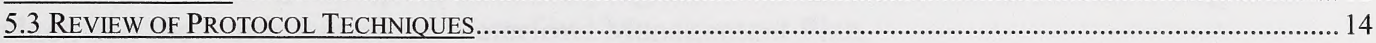

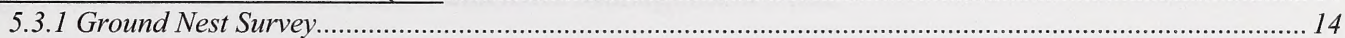

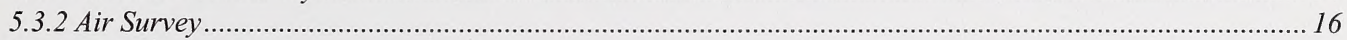

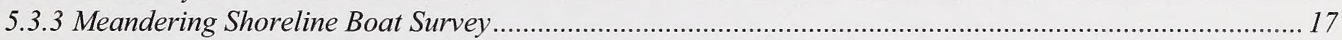

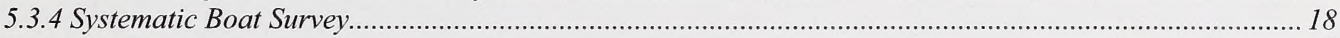

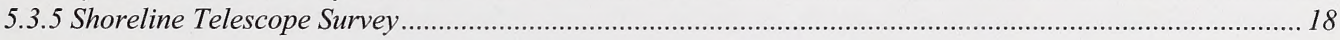

6.0 MANAGEMENT IMPLICATIONS AND FUTURE DIRECTIONS ............................................... 19

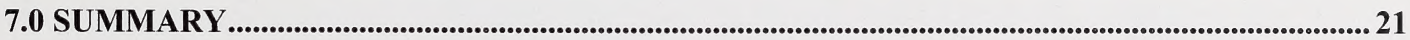

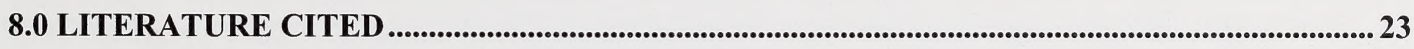

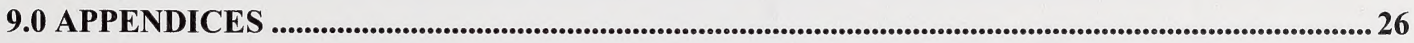

APPENDIX 1 Map of Alberta, THE StOny Plain STUdy AREA AND DISTRIBUTION OF GREBE COLONIES ..............27

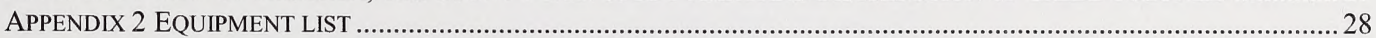

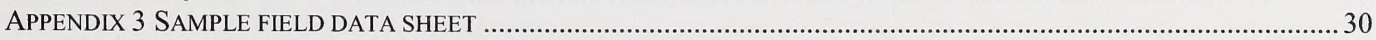

Appendix 3.1 Blank Waterbird Survey Data Sheet (Meandering Shoreline Boat Survey) ................................ 30

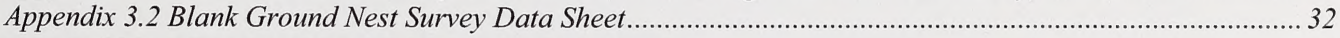

APPENDIX 4 MEANDERING SHORELINE BOAT SURVEY METHOD ................................................................. 34

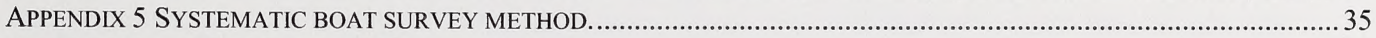

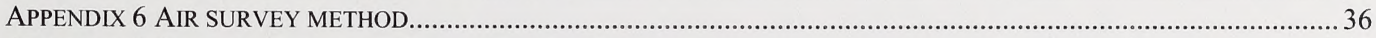

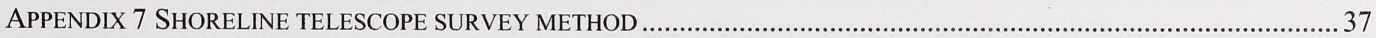

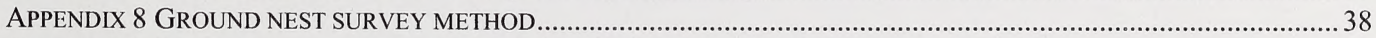

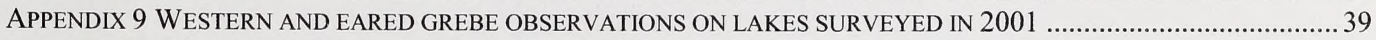

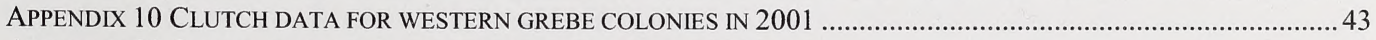

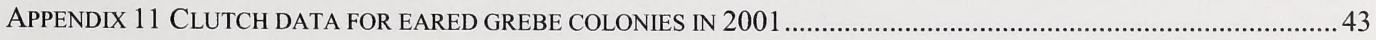




\section{LIST OF TABLES}

Table 1. Summary of western grebe data from 2001 surveys.....................................

Table 2. Summary of eared grebe data from 2001 surveys....................................... 


\section{ACKNOWLEDGEMENTS}

We would like to recognise the many individuals who assisted with this project. Field data collection was made possible with the help of Jan Fitch, Craig Hockley, Anne Hubbs, and Troy Sorensen, of Alberta Sustainable Resource Development; Sheldon Kowalchuk, Rich Rudolff, and Jan Young of the Alberta Conservation Association; Troy Wellicome of the Canadian Wildlife Service; and Frank Hanus, Jack Kinnaird, and Brendan McGlynn who kindly volunteered their time. Morley Riske generously provided his expertise on grebe ecology and surveying techniques, accompanied us on field surveys, and inspired us all with his dedication to grebe conservation. Andre Breault, of the Canadian Wildlife Service in Vancouver, also provided us with his expertise in grebe ecology and surveying techniques. Andrea Thompson conducted fieldwork, data management, and edited an earlier draft of this report, for which we are very grateful. We sincerely appreciate the logistical assistance provided to us by Alberta Fish and Wildlife Division Conservation Officers, namely: Quentin Deering, Cody Laroux, Francesco Marchet, Milt McKee, Kelly Moran, and Todd Stephenson. For their extensive experience flying wildlife surveys, we were fortunate to have Brock Allison and Aaron Beattie of Allison Air Service as our pilots for the aerial surveys. Administrative assistance provided by Mica Wickramasekara of the Alberta Environment Library and Kelly Williams is also greatly appreciated. Funding was provided by the Government of Alberta Species at Risk program and Fish and Wildlife Division Regional Budget, and the North American Waterfowl Management Plan. 


\section{EXECUTIVE SUMMARY}

This project focused on western grebes (Aechmophorus occidentalis) and eared grebes (Podiceps nigricollis), inhabiting the Stony Plain area, which is within the parkland and boreal natural regions of central Alberta, Canada. These grebe species have a wide distribution across western and central North America, yet indications are that they may be declining and could become threatened over the long-term. Nevertheless, relatively little research and monitoring attention has been directed toward these species. To address some of these concerns, we conducted surveys designed to locate grebe colonies, estimate population sizes, and assess their reproductive success. We also developed, tested, and evaluated various survey methods, thereby providing a framework for future surveys. In doing so, trend data can now be gathered for western and eared grebes, which will enable local and regional status assessments. Management implications are also provided in this report.

A population of approximately 2570 adult western grebes was estimated within the Stony Plain area (52 lakes), most of which inhabited only three lakes. Mean clutch sizes ranged from 1.8 to 2.8 eggs/nest ( $n=433$ nests, three colonies), and only $34 \%$ of nests were active ( $n=1271$ nests, three colonies), which implies a low reproductive success rate. Our results suggest that cumulative effects are negatively impacting western grebes locally and regionally, namely due to habitat loss, human disturbance, and water level declines. This is particularly apparent at the Wabamun Lake colony. The Wabamun Lake and Lac Ste. Anne colonies are considered nationally important to western grebes.

Regionally, eared grebes are currently more numerous and more widespread within the Stony Plain area than western grebes. Approximately 7627 eared grebes were observed on 15 lakes $(\mathrm{n}=52$ lakes), with nesting confirmed on 10 lakes. The mean clutch size for eared grebes ranged from 2.2 to 2.8 eggs/nest ( $\mathrm{n}=446$ nests, three colonies), and a large proportion of nests were active ( $88 \%, \mathrm{n}=512$ nests, three colonies), which suggests that reproductive success is within the natural range of variation. While eared grebes appear to be abundant and widely distributed regionally, they seem vulnerable locally due to similar disturbances that affect western grebes. This was revealed by their preference to colonise lakes or portions of lakes with relatively little human presence. The George Lake colony is considered nationally important to eared grebes, while colonies on Oldman Lake, Lac Ste. Anne, and Isle Lake are regionally important. 


\subsection{INTRODUCTION}

Western grebes (Aechmophorus occidentalis) and eared grebes (Podiceps nigricollis) are part of the family Podicipedidae, an ancient species of diving specialists that rarely fly except to migrate. These grebe species are colonial nesting waterbirds that build precarious floating nests of aquatic vegetation either secured to emergent vegetation or free-floating. Both species have wide distributions across western and central North America, with some colonies having thousands of nests. Indications are, however, that western and eared grebes may be declining (Burger 1997 and Koonz and Rakowski 1985) and could become threatened over the long-term. From the global perspective, nearly one quarter of the 22 grebe species worldwide are considered threatened by extinction (O'Donnel and Fjeldsa 1997). Currently in Alberta, western grebes are listed as "sensitive", while eared grebes are listed as "secure" (Alberta Sustainable Resource Development 2001), yet their status has not been fully evaluated. Furthermore, several specific threats to western and eared grebes have recently been identified that could have potential long-term effects on their populations. Although the status of western and eared grebes is now becoming a concern, relatively little research and monitoring attention have been directed toward these species.

The lack of research and monitoring directed toward western and eared grebes are attributed to three primary factors. First, their morphology and behaviour make them difficult to census using traditional air and boat surveying techniques. Both species spend considerable amounts of time underwater and often nest among emergent vegetation where they are obscured from view, and they have strong avoidance behaviours in the presence of humans. Second, their overall population has traditionally been perceived as somewhat secure, likely because some localised populations have thousands of birds (Hanneman and Heckbert 2001, O'Donnel and Fjeldsa 1997). Third, neither western nor eared grebes are game species, which historically has precluded them from receiving high research, monitoring, or management priority. In Alberta, much of the historic information that does exist for western and eared grebes has been collected from general waterbird surveys or as incidental observations (e.g. Purdy et al. 1983). These data are useful for identifying lakes with presence of historic western and eared grebe populations, minimum relative abundance values, and occasionally the identification of colonies. Western and eared grebe population trends at local, regional, and provincial scales, as well as their reproductive biology, are poorly understood in Alberta. This project is the first of its kind in Alberta to address some of these knowledge gaps. Similar projects in Canada have been conducted in British Columbia (Breault et al. 1988) and in Manitoba (Koonz and Rakowski 1985).

Several factors have consistently been identified as key threats to western and eared grebe populations (Feerer and Garrett 1977, Koonz and Rakowski 1985, Kristensen and Nordstrom 1979, Nuechterlein 1975, Riske 1976, and Short 1984). It is important to note that single and localised events can have dramatic negative implications to entire populations of western and eared grebes, due to their colonial behaviour. The primary natural threats include water level fluctuations, wind storms, egg depredation, and disease. Human threats include alterations to breeding habitat (i.e. emergent vegetation clearing, lake water level manipulations, and ranching and agricultural practices), human disturbances of nesting and feeding birds (e.g. visual, auditory, and wave disturbances from boaters), historical hunting for food and plumage, introduction of sport fish (which may out compete native prey species), and introduction of pollutants, which may bioaccumulate and biomagnify. The long-term effects of these threats, if left unmitigated, have the potential to jeopardise western and eared grebe populations in Alberta, and throughout their range. 
This project was designed to address concerns of potential western and eared grebe population declines and existing knowledge gaps by fulfilling the following objectives:

1) Update the status of historic populations and colonies on lakes within the Stony Plain study area (Appendix 1);

2) Inventory as many other lakes as possible within the study area to identify those with active western and eared grebe populations, locate new colonies, and determine overall population estimates for the study area;

3) Develop, test, and evaluate various surveying techniques, and recommend a standardised set of protocols that can be used in future surveys of this kind across the province;

4) Measure the reproductive success of selected western and eared grebe colonies; and

5) Identify mitigative measures that address the primary threats to western and eared grebes within the study area.

This report provides an overview of the project. An internal government report of supplemental information provides specific details for each lake with historic and active western and eared grebe colonies (i.e. lake description and access, survey methods, results, colony descriptions and locations, and potential colony threats), which can be made available upon specific request. A literature and data review for Alberta is also being conducted as part of this project in order to develop an inventory of lakes with colonial grebe populations and nesting areas, and to evaluate the existing knowledge base, and will be provided in a future report.

\subsection{STUDY AREA}

The study area of this project is located in central Alberta (Appendix 1), and includes the counties of Barrhead, Lac Ste. Anne, Parkland, and Westlock. The legal land description for the study area includes townships 48 to 66 and ranges 23 to 28 west of the fourth meridian, and townships 48 to 66 and ranges one to nine west of the fifth meridian (i.e. between $53^{\circ}$ and $55^{\circ}$ north latitude, and $113^{\circ}$ and $115^{\circ}$ west longitude). The north/south and east/west maximum distances are approximately $143 \mathrm{~km}$ and $135 \mathrm{~km}$, respectively, while the total area is $11592.6 \mathrm{~km}^{2}$. Although Chip Lake is located $17 \mathrm{~km}$ west of the study area, it was included in the survey due to its relative proximity.

The study area is located within the parkland and boreal forest natural regions (Alberta Environmental Protection 1994a). It is within an agricultural dominated landscape, otherwise known as the White Area (Alberta Environmental Protection 1994b, Public Lands 2001), where much of the original vegetation has been cleared for agricultural (i.e. cereal and forage crops, and pastureland), urban, and industrial development. Those forested areas that remain are mixedwoods, dominated by deciduous species, i.e. trembling aspen (Populus tremuloides Michx.), balsam poplar (Populus balsamifera L.), and white birch (Betula papyrifera Marsh.), and small amounts of coniferous species, i.e. white spruce (Picea glauca), black spruce (Picea mariana Mill.), Jack pine (Pinus banksiana Lamb.), tamarack (Larix laricina) and balsam fir (Abies balsamea L.). A total of 52 lakes were surveyed, representing the majority of lakes within the study area. They are located in either the North Saskatchewan or Athabasca River basins, are generally meso- to hyper- eutrophic, and range in size from less than 50 ha to nearly 8000 ha. Several lakes are described in Mitchell and Prepas (1990). The proximity of the study area to several urban centres, such as the city of Edmonton, make many of these lakes attractive for 
recreation and cottage development. Precipitation levels during the winter of 2000/01 were low throughout much of the study area. This trend continued into the spring and early summer of 2001 , resulting in substantial reductions in lake water levels and subsequent exposure of previously submerged lakebed.

\subsection{METHODS}

Field surveys occurred between June 4, 2001 and August 9, 2001, with the majority of surveys conducted in June and early July to coincide with the peak nesting period (Kristensen and Nordstrom 1979, Lindvall and Low 1982, and McAllister 1958). We surveyed a total of 52 lakes, with some lakes surveyed several times and using multiple techniques. Before the onset of the field season, a literature and database review was conducted to identify lakes with historic populations of western and eared grebes and/or presence of colonies. These lakes were given the highest priority for surveying. As many other lakes as possible were surveyed based on logistical considerations. Surveys were conducted during morning hours while light, weather, and wind conditions were most favourable. Inclement weather (i.e. high winds, cold temperatures, and rain) was generally avoided. Waterbirds other than western and eared grebes were also recorded and will be summarised in a future report.

A variety of field survey techniques were used to estimate western and eared grebe population sizes, locate colonies, estimate numbers of nests, and assess reproductive success. We termed these techniques as the meandering shoreline boat survey, systematic boat survey, air survey, shoreline telescope survey, and ground nest survey. A general description of each survey technique is provided below. Overall, we surveyed most of the lakes in the Stony Plain study area by plane, and surveyed the majority of lakes supporting colonies from the ground. Survey methods were often adjusted slightly for each lake in order to overcome specific logistic challenges. The British Columbia Ministry of Environment, Lands and Parks Resource Inventory Branch (1998) also provide details and considerations for several techniques designed specifically for surveying western and eared grebes. Colony locations were recorded using Garmin handheld GPS units. Location co-ordinates were in degrees, minutes, and seconds using NAD 83, and later converted into UTMs. For larger colonies, several GPS locations were recorded along their perimeter to provide an index of size. Recommended equipment for conducting surveys is provided in Appendix 2, and sample field data sheets are provided in Appendix 3.

\section{$\underline{3.1 \text { Meandering Shoreline Boat Survey }}$}

Meandering shoreline boat surveys (Appendix 4) were conducted using either powerboats or canoes, depending on the size, depth, and access considerations of the waterbody. Powerboatbased surveys used between four and five observers (including one driver), whereas canoe-based surveys were conducted with two observers. The primary objective of this survey technique was to locate active colonies. Survey routes typically followed the shoreline and encircled islands at distances ranging from $20 \mathrm{~m}$ to $200 \mathrm{~m}$ depending on quality of nesting habitat and water depth. Achieving relative abundance estimates was also attempted by modifying routes to include groups of western or eared grebes observed swimming in open water areas. While surveying from powerboats, speeds varied between approximately $35 \mathrm{~km} / \mathrm{hr}$ and $45 \mathrm{~km} / \mathrm{hr}$ in areas with poor grebe nesting habitat (e.g. exposed southwest shorelines with no emergent vegetation present). Speeds ranged from $0 \mathrm{~km} / \mathrm{hr}$ to $15 \mathrm{~km} / \mathrm{hr}$ if nesting potential was high and/or large numbers of western or eared grebes were observed. Viewing distances ranged considerably depending on the 
weather conditions. In calm winds and bright light conditions, viewing distances were as far as $200 \mathrm{~m}$ with the aid of binoculars, but this was reduced to less than $75 \mathrm{~m}$ during less than ideal conditions. We conducted meandering shoreline boat surveys between June 4, 2001 and August 9, 2001, with June being the most intense surveying period. Generally, one lake per morning was surveyed using this technique. Meandering shoreline boat surveys required between two to five hours to complete for each lake.

\subsection{Systematic Boat Survey}

The systematic boat survey (Appendix 5) was designed to census adults and broods of western grebes. This technique was only conducted on Wabamun Lake (July 23, 2001) and Lac Ste. Anne (July 27, 2001), and only used powerboats. Between four and five observers (including one driver) were used for each survey. These lakes were surveyed in an east to west direction (to ensure observers were looking generally away from the sun) along zigzag transects routed in northwest/southwest directions between north and south shores. Speeds were typically between $30 \mathrm{~km} / \mathrm{hr}$ and $45 \mathrm{~km} / \mathrm{hr}$ for these surveys, but were temporarily reduced to $0 \mathrm{~km} / \mathrm{hr}$ to $15 \mathrm{~km} / \mathrm{hr}$ when larger groups of western grebes were encountered. Because surveys were conducted on days with ideal weather conditions (i.e. low wind speeds and clear skies), viewing distances ranged in excess of $200 \mathrm{~m}$ with the aid of binoculars, which determined the spacing of the transects. When compared to the meandering shoreline boat survey, the systematic boat survey was conducted at higher overall speeds, required less time to execute, and focused on surveying the open water areas as opposed to along the shoreline. These factors were considered critical for improving the population estimates. This technique was not tested on eared grebe populations, since most populations were located on lakes not conducive to powerboats. Systematic boat surveys required approximately two hours to complete per lake.

\section{$\underline{3.3 \text { Air Survey }}$}

Three air surveys were conducted (June 19, 2001, June 21, 2001, and July 6, 2001), resulting in nearly complete coverage of the study area. The first two air surveys used a Cessna 180 fixedwing plane, while the third survey used a Supercub fixed-wing plane affixed with floats. Surveys with the Cessna 180 used one pilot and two observers, while the survey using the Supercub used one pilot and one observer. Each air survey lasted over seven hours, and included between eight and 20 lakes each, depending on the lake sizes and number of colonies encountered. The first survey included eight lakes within the southern and western portions of the study area, most of which were large and had historic western and eared grebe colonies. The second survey of 14 lakes focused on the northern half of the study area. Finally, the third survey of 20 lakes was conducted primarily in the southeastern portion of the study area, where lakes are generally small and no western or eared grebe populations were observed. Weather conditions were ideal for flying each day, with clear skies, low wind speeds (i.e. less than $30 \mathrm{~km}$ ), and moderately warm temperatures (i.e. maximum daily temperatures between $20^{\circ} \mathrm{C}$ and $25^{\circ} \mathrm{C}$ ) prevailing.

The primary objectives of the air surveys were to reconnoitre the study area for colonial grebe nesting locations, identify lakes with western and/or eared grebe populations, and provide a comparison to ground surveys. To meet these objectives, flight lines were directly over the lake shorelines (Appendix 6), with observers looking downward into the stands of emergent aquatic vegetation and toward the centre of the lake. For larger waterbodies, a transect was flown through the centre of the lake and observations were made on either side of the plane. In areas with large and dense stands of emergent aquatic vegetation, several passes were made to verify the presence or absence of colonies. When colonies were located, several passes at slower speeds and lower 
elevations were flown in order to estimate the number of nests. Flight speeds varied between 110 $\mathrm{km} / \mathrm{hr}$ and $240 \mathrm{~km} / \mathrm{hr}$, and elevations varied from $25 \mathrm{~m}$ to $200 \mathrm{~m}$ above ground level. Air surveys typically required five to 30 minutes to complete for each lake. Photographs of numerous colonies were taken during the air surveys for documentation purposes, and to test if nests could be counted from the photos. Only the Wabamun Lake western grebe colony photographs were suitable for testing this nest counting technique, since photograph quality was chronically poor for the other colonies (attributed to light glare, large colony size, flying height and angle, and poor visibility of nests through the emergent vegetation). Photographs of the Wabamun Lake colony were digitised, a grid was superimposed over the images, and the nests were then systematically counted.

\subsection{Shoreline Telescope Survey}

On small waterbodies with poor access, shoreline telescope surveys were conducted to determine the presence of western and eared grebes and/or their colonies (Appendix 7). Several survey locations were established along the shore to ensure full coverage of each waterbody. Landmarks were used as boundaries between surveys to minimise double counting of observations.

Depending on wind and light conditions, viewing distances ranged between $75 \mathrm{~m}$ and $200 \mathrm{~m}$ with the aid of the telescope affixed to a tripod. This survey technique has the benefit of not being overly intrusive. Shoreline telescope surveys were conducted using two observers, and typically required less than one hour to complete per lake.

\section{$\underline{3.5 \text { Ground Nest Survey }}$}

Ground nest survey techniques differed depending on whether or not colonies were located within stands of emergent aquatic vegetation, or in open water areas. Surveys conducted within stands of emergent vegetation used teams of one to six observers (depending on the size of the colony), who entered directly into the colonies wearing chest waders. Colonies were surveyed along parallel belt transects five meters to $18 \mathrm{~m}$ wide (depending on the number of observers), and ran along the shoreline (Appendix 8). When multiple observers were used, they arranged themselves perpendicular to the shoreline and were spaced three to four meters apart. Observers then followed their individual transects in unison to prevent either double counting or missing nests. The area of each colony furthest from the shoreline was surveyed first, with the individual nearest the shore marking the transect line using flagging tape or a $100 \mathrm{~m}$ measuring tape. Transects ended when observers no longer encountered nests. Once the end of the colony was reached, the observers realigned themselves on the opposite side of the marked transect and travelled to the opposite end of the colony. This was repeated until observer(s) no longer encountered nests, thus achieving a near total count of nests. Lakes with western grebe colonies surveyed in this fashion included Isle Lake (June, 14 and 17, 2001), Lac Ste. Anne (June 26, 2001), and Wabamun Lake (June 27, 2001). The only eared grebe colony surveyed using this technique was located on Isle Lake (June, 14 and 17, 2001). The ground nest survey was repeated within the Wabamun Lake colony on July 23, 2001, in order to determine the efficacy of counting nests following hatching and colony abandonment. For this particular survey, we recorded the state of nest decay as intact, partially floating, or sunken. Ground nest surveys required between one and three hours to complete depending on colony size. Individual transects through the central core of colonies required 15 to 30 minutes each to complete.

Having surveyors directly within the colony during the breeding season enabled them to record several measures of reproductive success. We recorded clutch sizes, the presence of egg fragments from successful hatching events or egg depredation, and the number of chicks. 
Distinguishing between successful hatching events and egg depredation was often difficult. Shell fragments identified as successful hatching events were recorded if the egg membrane was present in the nest and the egg was broken into two neat pieces, one being generally larger than the other (Baicich and Harrison 1997). Shell fragments were identified as a depredation event if the egg had a distinguishable hole in its side with the undeveloped embryo either partially or completely consumed, and no egg membranes were present in the nest. Active nests were considered any nest with eggs and/or chicks. Empty nests were included within the total count of nests for each colony, and nests that appeared to be abandoned and/or damaged were noted as such. A mean and modal clutch size was determined from each ground nest survey. While in the colonies we also made general site notes describing the habitat, which included aquatic vegetation species composition, colony length and width measurements, and water depths.

The majority of eared grebe colonies identified in 2001 were located in open water areas, where water depths necessitated the use of a canoe for conducting a modified version of the ground nest survey. This technique was used for colonies located on Brock Lake (June 29, 2001), George Lake (June 28, 2001), and Lac Ste. Anne (June 26, 2001). These surveys were conducted using teams of two to four observers in one or two canoes, respectively. One observer in each canoe manoeuvred the canoe, while the other counted nests with the aid of binoculars. Depending on the colony size, observations were made either from a stationary position at the edge of the colony, or from a moving canoe travelling approximately $30 \mathrm{~m}$ from the edge of the colony. Multiple counts from various points were conducted, and a mean value was used as the final nest count estimate. Since eared grebes seemed less agitated by our presence than western grebes, often a count of nesting adults present within the colony was possible. These ground nest surveys required one to two hours to complete. A canoe-based ground nest survey of the Lac Ste. Anne eared grebe colony was repeated on July 27, 2001 to determine if nests could be counted following colony abandonment.

When wind conditions were calm, we entered eared grebe colonies via canoe to collect reproductive data. A single six meter belt transect was established through the approximate centre of the colony. All nests within this transect were counted and clutch size, hatching events, egg depredation, and chicks were also recorded. This was only conducted on eared grebe colonies on Brock Lake and Lac Ste. Anne, and required 10 minutes to 15 minutes to complete. Due to unfavourable wind conditions at the time of the survey, reproductive measures were not conducted on the George Lake eared grebe colony.

\subsection{RESULTS}

A total of 52 lakes were surveyed in 2001, representing nearly all lakes over 100 ha in size within the Stony Plain study area. A summary table of results, survey dates, and methods used for each lake surveyed in 2001 is provided in Appendix 9. Although some lakes were surveyed several times using different techniques, we only provide one set of results from the surveys we considered most accurate (Appendix 9). A summary of population and colony data is provided in Table 1 for western grebes, and Table 2 for eared grebes. Clutch data for western and eared grebes are provided in Appendices 10 and 11, respectively.

To clarify several terms used throughout the report we provide the following definitions and descriptions. A colony is a group of nests spaced relatively closely together within a given area. We refer to a population as a group of western or eared grebes within a given area, the individuals 
of which may or may not include non-breeders. A local population refers to a group of western or eared grebes within a single lake, and a regional population is the total number of western or eared grebes within the Stony Plain study area. Mean and modal clutch size was calculated by only including nests with at least one egg and/or chick.

\subsection{Western Grebes}

Of the lakes surveyed, three had substantial western grebe colonies (i.e. Lac Ste. Anne, Wabamun Lake, and Isle Lake,). Small populations of adult western grebes were observed on two additional lakes (i.e. Thunder Lake and Lac La Nonne), but nesting was not confirmed. Within the Stony Plain study area (Appendix 1), we estimated a total of 2570 adult western grebes, a total of 1271 nests, an overall mean clutch size of 2.3 eggs/nest ( $n=433$ nests in three colonies), an overall modal clutch size of 2 eggs/nest $(n=433)$, and we estimated that $34 \%$ of nests $(n=1271$ nests in three colonies) were active (Table 1). Lakes with the largest adult western grebe populations were Lac Ste. Anne and Wabamun Lake, which represented $49 \%$ and $44 \%$ of the overall population in the study area, respectively. Similarly, these lakes had the largest number of nests. Western grebes on Isle Lake nested in two relatively small colonies, which had substantially higher mean and modal clutch sizes and percentage of active nests, when compared to the Lac Ste. Anne and Wabamun Lake colonies (Table 1). Two ground nest surveys were conducted on the Wabamun Lake western grebe colony: the first survey sampled a subset of 127 nests (approximately $23 \%$ of the colony) through the centre of the colony (June 20,2001), and the second survey was conducted throughout the colony and reported in Table 1 (June 27, 2001). From the second survey, the mean clutch size was 2.1 eggs/nest, the modal clutch size was 1 egg, the maximum clutch size was four eggs, and $30 \%$ of nests were active.

All colonies were located within stands of emergent vegetation, dominated by bulrush (Scirpus spp.), where water depths ranged from approximately $40 \mathrm{~cm}$ to $150 \mathrm{~cm}$. The two western grebe colonies found on Isle Lake were located adjacent to small islands, while colonies on Lac Ste. Anne and Wabamun Lake were located adjacent to the shoreline. Western grebes were present only on the largest lakes of the study area, which ranged in size from 816.0 ha (Thunder Lake) to 7925.6 ha (Wabamun Lake). All lakes with historical records of western grebes (Purdy et al. 1983, Riske 1976) still had western grebes present in 2001, with the exception of Big Lake, although anecdotal information suggests that numbers in some locations have declined.

Table 1. Summary of western grebe data from 2001 surveys.

\begin{tabular}{|l|c|c|c|c|c|c|}
\hline Lake Name & $\begin{array}{c}\# \text { of } \\
\text { Adults }\end{array}$ & $\begin{array}{c}\# \text { of } \\
\text { Colonies }\end{array}$ & $\begin{array}{c}\# \text { of } \\
\text { Nests }\end{array}$ & $\begin{array}{c}\text { Mean Clutch Size } \\
\text { (Eggs/Nest) }\end{array}$ & $\begin{array}{c}\text { Modal Clutch Size } \\
\text { (Eggs/Nest) }\end{array}$ & $\begin{array}{c}\text { \% Active } \\
\text { Nests }\end{array}$ \\
\hline Isle Lake & 154 & 2 & 77 & $2.8^{*}$ & $3^{*}$ & $91^{\tau}$ \\
\hline Lac La Nonne & 25 & Unknown & - & - & - & - \\
\hline Lac Ste. Anne & 1268 & 1 & 634 & $2.3^{* *}$ & $2^{* *}$ & $47^{\tau \tau}$ \\
\hline Thunder Lake & 3 & Unknown & - & - & - & - \\
\hline Wabamun Lake & 1120 & 1 & 560 & $1.8^{* * *}$ & $1^{* * *}$ & $11^{\tau \tau \tau}$ \\
\hline Total & $\mathbf{2 5 7 0}$ & $\mathbf{4}$ & $\mathbf{1 2 7 1}$ & $\mathbf{2 . 3}^{* * * *}$ & $\mathbf{2}^{* * * *}$ & $\mathbf{3 4}^{\tau \tau \tau \tau}$ \\
\hline
\end{tabular}

${ }^{*} \mathrm{n}=70$ nests. ${ }^{* *} \mathrm{n}=301$ nests. ${ }^{* * *} \mathrm{n}=62$ nests. ${ }^{* * * *} \mathrm{n}=433$ nests: ${ }^{\tau} \mathrm{n}=77$ nests. ${ }^{\tau \tau} \mathrm{n}=634$ nests. ${ }^{\tau \tau \tau} \mathrm{n}=560$ nests ${ }^{\tau \tau \tau \tau} \mathrm{n}=1271$ nests.

\subsection{Eared Grebes}


Eared grebes were present on 15 lakes, and colonies were confirmed on 10 lakes. Within the Stony Plain study area (Appendix 1), the total adult eared grebe population was estimated at 7627 , with an estimated total of 3688 nests (Table 2). Clutch counts were conducted on three colonies (i.e. Brock Lake, Isle Lake, and Lac Ste. Anne colonies). We estimated that $88 \%$ of nests were active ( $\mathrm{n}=512$ nests), with an overall mean clutch size of 2.6 eggs/nest ( $\mathrm{n}=446 \mathrm{nests})$, and an overall modal clutch size of 3 eggs/nest $(n=446)$. The largest eared grebe colony, with approximately 1666 nests, and largest population, representing $44 \%$ of the overall population, was observed on George Lake (Table 2). Of the remaining lakes with eared grebe populations present, three had large populations over 500 individuals, six lakes had medium sized populations between 100 and 500 individuals, and five lakes had small populations with less than 100 individuals (Table 2). Three colonies in addition to the George lake colony had more than 250 nests, five had mid sized colonies with between 50 and 250 nests, and one colony had less than 50 nests (Table 2 ). Unlike the western grebe colonies, only two of the 10 eared grebe colonies were located among emergent or floating leafed aquatic vegetation. The colony on Isle Lake was located within a stand of bulrush, while the colony on Arthur Lake was located among small yellow pond-lilies (Nuphar variegatum Engelm.). Lakes with eared grebes varied greatly in size, from 51 ha (unnamed lake south of Lac Ste. Anne) to 7420 ha (Chip Lake); however, most were smaller than 500 ha. Of the historical eared grebe populations and colonies (Purdy et al. 1983 and Folinsbee 1989), the Big Lake and Romeo Lake populations appeared to be completely absent in 2001, and the Majeau Lake population underwent a significant decline. We discovered twelve lakes with no previous record of eared grebes (i.e. Arthur Lake, Brock Lake, Chip Lake, Devil's Lake, George Lake, Kakina Lake, Kirchner Lake, Oldman Lake, Thunder Lake, unnamed lake south of Lac Ste. Anne, unnamed lake south of Stony Plain, and Wakomao Lake).

Table 2. Summary of eared grebe data from 2001 surveys.

\begin{tabular}{|c|c|c|c|c|c|c|}
\hline Lake Name & $\begin{array}{c}\text { \# of } \\
\text { Adults } \\
\end{array}$ & $\begin{array}{c}\text { \# of } \\
\text { Colonies } \\
\end{array}$ & $\begin{array}{c}\text { \# of } \\
\text { Nests }\end{array}$ & $\begin{array}{c}\text { Mean Clutch Size } \\
\text { (Eggs/Nest) }\end{array}$ & $\begin{array}{c}\text { Modal Clutch Size } \\
\text { (Eggs/Nest) }\end{array}$ & $\begin{array}{c}\% \text { Active } \\
\text { Nests }\end{array}$ \\
\hline Arthur Lake & 120 & 1 & 60 & - & - & - \\
\hline Brock Lake & 484 & 1 & 242 & $2.2^{*}$ & $2^{*}$ & $96^{\tau}$ \\
\hline Chip Lake & 130 & 1 & 65 & - & - & - \\
\hline Devil's Lake & 28 & Unknown & - & - & - & - \\
\hline George Lake & 3332 & 1 & 1666 & - & - & - \\
\hline Isle Lake & 794 & 1 & 397 & $2.6^{* *}$ & $3^{* *}$ & $98^{\tau \tau}$ \\
\hline Kakina Lake & 60 & 0 & - & - & - & - \\
\hline Kirchner Lake & 280 & 1 & 140 & - & - & - \\
\hline Lac Ste. Anne & 934 & 1 & 467 & $2.8^{* * *}$ & $3^{* * *}$ & $85^{\tau \tau \tau}$ \\
\hline Majeau Lake & 50 & Unknown & - & - & - & - \\
\hline Oldman Lake & 1120 & 1 & 560 & - & - & - \\
\hline Thunder Lake & 110 & Unknown & - & - & - & - \\
\hline $\begin{array}{l}\text { Unnamed Lake } \\
\text { (South of Lac } \\
\text { Ste. Anne) }\end{array}$ & 62 & 1 & 31 & - & - & - \\
\hline $\begin{array}{l}\text { Unnamed Lake } \\
\text { (South of Stony } \\
\text { Plain) }\end{array}$ & 120 & 1 & 60 & - & - & - \\
\hline Wakomao Lake & 3 & Unknown & - & - & - & - \\
\hline Totals: & 7632 & 10 & 7627 & $2.6^{\text {*3** }}$ & $3^{* * * *}$ & $\mathbf{8 8}^{\tau \tau \tau \tau}$ \\
\hline
\end{tabular}

${ }^{*} \mathrm{n}=26$ nests. ${ }^{* *} \mathrm{n}=334$ nests. ${ }^{* * *} \mathrm{n}=86$ nests. ${ }^{* * * *} \mathrm{n}=446$ nests. ${ }^{\tau} \mathrm{n}=27$ nests: ${ }^{\tau \tau} \mathrm{n}=397$ nests. ${ }^{\tau \tau} \mathrm{n}=88$ nests ${ }^{\tau \tau \tau \tau} \mathrm{n}=512$ nests. 


\subsection{DISCUSSION}

From our surveys conducted in 2001, we updated records of historic western and eared grebe populations and colonies, as well as provide an extensive inventory throughout the Stony Plain study area. We estimated both local and regional population sizes for western and eared grebes, as well as measured their reproductive success. Finally, we developed, tested and evaluated various surveying protocols, and identified a series of management concerns.

\section{$\underline{5.1 \text { Western Grebes }}$}

Relatively few lakes within the Stony Plain study area support western grebe populations. However, they appear to have a high affinity to certain lakes, since current populations on Isle Lake and Wabamun Lake have been present in excess of 20 years (Purdy et al. 1983), and in excess of 30 years on Lac Ste. Anne (Riske 1976). No historic lake populations, that we are aware of, have become extinct within the study area. The only potential exception to this was the Big Lake population observed by Purdy et al. (1983); however, given the small number observed (i.e. three adults) it is unclear whether or not this was a remnant of a larger population or some transient non-breeders. Population trends could not be derived due to different objectives and sampling techniques between surveys. Riske (1976) conducted grebe surveys on Lac Ste. Anne in the early 1970's that provide the best comparison. At that time, western grebes appeared to be declining due to habitat loss, boating disturbances, and bioaccumulation effects of pesticides, but on the last year of this study western grebes increased in numbers. Since then, the population appears to have stabilised or slightly increased in number, presumably due in part to legislation that bans the use of harmful pesticides like DDT. Nevertheless, there are indications that the western grebe population in the study area, although currently sizeable ( 2570 adults), is being negatively impacted by the cumulative effects of several factors, especially at Wabamun Lake.

Western grebes have specific requirements for lake colonisation, including: sizeable fish populations, minimal human activity, areas protected from wind and waves, large open water areas, relatively stable water levels, and persistent emergent or floating leafed vegetation for nesting, i.e. bulrush, common cattails (Typha latifolia L.), reed grass (Phragmites communis Trin.), and occasionally small yellow pond-lilies (Koonz and Rakowski 1985, Kristensen and Nordstrom 1979, Nuechterlein 1975, Riske 1976, and Short 1984). Only a handful of lakes within the study area meet most or all of these requirements. This explains why so few lakes currently have sizeable western grebe populations and why no new lakes have been colonised since the last waterbird survey in the study area (Purdy et al. 1983). It also highlights the importance of some local populations at the regional or even national level. For instance, a federal initiative to prioritise migratory bird habitats identifies Lac Ste. Anne as being nationally important for western grebes (Poston et al. 1990). In northwestern Alberta, Hanneman and Heckbert (2001) also reported a sizeable regional western grebe population (i.e. 2432), which was confined to a relatively small number of lakes (i.e. three of 36 lakes surveyed).

Burger (1997) identified boating disturbances, shoreline development practices, and water level declines as the primary causes of western grebe population extinction on several British Columbia lakes. These also appear to be the leading threats within the Stony Plain study area. Boating disturbances, such as wave, visual, and auditory disturbances, appear to render otherwise viable habitat inadequate for nesting. The dramatic rise in powerboating activity on Alberta lakes and increase in their speed capabilities is exacerbating this problem. Boating disturbances are further compounded by the popularisation of personal watercrafts, which can access shallow areas and 
potentially affect nesting colonies. Western grebes occasionally nest in open water areas (Lindvall and Low 1982); however, this is unlikely to occur within the Stony Plain study area due to human disturbances, which further limits potential nesting habitat. The effects of motorised boats on western grebes are likely best exemplified at Lac Ste. Anne. Two historic colonies identified here (i.e. at the narrows separating the east and west basins) by Purdy et al. (1983) were no longer active in 2001. Although emergent vegetation habitat is still abundant at the historic nesting sites, this location has considerable boating traffic along both shorelines, which presumably produces enough disturbances to prevent western grebes from using this area. Instead, the current western grebe colony seems to have re-located to a more secluded section of the shoreline, suggesting avoidance behaviour.

The potential long-term effects of boating disturbance on western grebes may have already occurred at Lac La Nonne and Thunder Lake. These lakes appear to have the characteristics necessary to sustain sizeable western grebe populations, yet very few individuals were observed in 2001. These individuals may represent remnants of historically larger populations that have declined as a result of reduced habitat availability caused by increased human presence and disturbance. This argument is further supported by observations made by a naturalist and longtime cottage owner at Thunder Lake, who noted approximately 100 western grebes in the late 1960 's, and a rapid decline following the establishment of Thunder Lake Provincial Park, development of boating access, and an overall increase in human presence (J. Kinnaird 2001, personal communication). To mitigate the effects of boating disturbance, Koonz and Rakowski (1985) recommended a $1000 \mathrm{~m}$ buffer surrounding all colonies, as well as a $600 \mathrm{~m}$ minimum altitude for aircraft. Regulations such as these are especially critical during the breeding period from approximately mid May to mid July.

The loss of habitat due to lakefront housing development and cattle grazing pressure is also a major threat to western grebes and their nesting habitat, and was identified as a major concern in Alberta nearly 30 years ago (Riske 1976). Often associated with lakefront housing development is the clearing of aquatic vegetation, development of public and private docks, and increased human presence, all of which lead to the fragmentation and loss of shoreline nesting habitat. As well, the pressure to increase and expand the cattle industry in Alberta is further compounding the concerns of shoreline habitat loss and degradation. It is imperative that portions of shoreline are left for natural and special cattle management techniques within riparian areas are implemented. Cattle management techniques, such as installation of remote watering systems, distributing salt blocks within upland areas, tree retention within riparian areas, and cattle rotation within riparian areas to late summer are several techniques that would protect lakeshores. Nesting habitat can be given protective status by applying provincial designations, such as protective notations (PNT) and the 'ecological reserve' status used in British Columbia (Koonz and Rakowski 1985), or by applying federal designations, such as migratory bird sanctuaries. The level of protection for each colony can be based on their local, regional and national ranking of importance. Poston et al. (1990), assigned these ranks for grebes, with western grebe colonies of over 500 nests or breeding pairs being nationally important, those with 100 to 500 nests or breeding pairs as regionally important, and colonies of any smaller size designated as locally important. With this ranking system, the colonies in Lac Ste. Anne and Wabamun Lake are of national importance, and should receive the maximum level of protection.

The relatively rapid decline of lake water levels within the Stony Plain study area, as a result of lower precipitation rates, is the third major threat that has rendered previously viable western grebe nesting habitat inadequate. This is also supported by the findings of Riske (1976), who states drastic water fluctuations within the breeding season can lead to a significant decrease in 
reproductive productivity. Smaller patches of nesting habitat, such as the nesting locations adjacent to the two small islands of Isle Lake, are particularly vulnerable to water level fluctuations. The disappearance of a historic colony along Horse Island in Lac Ste. Anne's middle basin (Figure 2.8) could be partially attributed to the low water levels in 2001. Western grebes typically require water depths in excess of $25 \mathrm{~cm}$, which enables underwater access to and from nests (Feerer and Garrett 1977, Kristensen and Nordstrom 1979, and Nuechterlein 1975). In 2001 large portions of emergent vegetation (e.g. bulrush) were growing in water less than $25 \mathrm{~cm}$ deep or on recently exposed lakebed, which indicates a relatively rapid decline of water levels from previous years. Given enough time, emergent vegetation will re-colonise new areas in response to fluctuating water levels; however, there is a time lag and in years of rapid water level changes, viable nesting habitat may be greatly reduced. For the three primary sources of habitat loss outlined above, i.e. boating disturbance, shoreline development, and water level fluctuations, the availability of alternative suitable habitats is critical for maintaining viable western grebe populations into the long-term.

Other concerns regarding status of western grebes, especially at Wabamun Lake and Lac Ste. Anne, relate to measures of reproductive success. Although they are relatively long lived (greater than 10 years; Eichhorst 1992), western grebes have low recruitment rates, thus reducing the potential for population growth. Riske (1976), for example, reported the mean number of young per adult most often between 0.60 and 0.73 on Lac Ste. Anne, and Forbes (1988) reported a mean number of young per adult as 0.79 on Duck Lake, British Columbia. Although our attempts at measuring fledgling success with systematic boat surveys were largely unsuccessful, we did observe relatively low mean and modal clutch sizes for the populations at Wabamun Lake (1.8 eggs/nest and 1 egg/nest, respectively) and Lac Ste. Anne (2.3 eggs/nest and 2 eggs/nest, respectively). Other studies reported higher mean clutch values: Lac Ste. Anne had an overall mean clutch size of approximately 3.0 eggs/nest (Riske 1976); Cold Lake had 3.6 eggs/nest (Kristensen and Nordstrom 1979); Duck Lake, British Columbia ranged from 3.2 to 3.7 eggs/nest between 1981 and 1983 (Forbes 1988); Shuswap Lake British Columbia had 2.9 eggs/nest (Forbes 1988); and Bear River Migratory Bird Refuge, Utah had 2.6 eggs/nest (Lindvall and Low 1982). Modal clutch sizes in other studies, which ranged between three and four eggs per nest (Herman et al. 1969, Nero 1959, and Riske 1976), were also larger than those of Lac Ste. Anne and Wabamun Lake colonies (Table 1). Furthermore, Kristensen and Nordstrom (1979) reported much higher proportions of active nests throughout the nesting period (i.e. $67 \%$ on June 8 and $95 \%$ on June 26), than those observed on Wabamun Lake (11\% on June 27 ) and Lac Ste. Anne ( $47 \%$ on June 22; Table 1). Considering that these two western grebe populations are the largest within the study area, representing $93 \%$ of the regional population, and that they may have national importance, their low reproductive success is a major concern.

Since western grebes (and eared grebes) are asynchronous egg layers, it was difficult to determine with certainty whether or not we surveyed during the peak nesting season. This could only be determined by conducting multiple surveys throughout the nesting season, (e.g. Kristensen and Nordstrom 1979). We believe, however, that the low reproductive success of western grebe colonies of Wabamun Lake and Lac Ste. Anne were the result of disturbance factors, and not due to poor timing of surveys. Western grebes may abandon nests when repeatedly disturbed (Riske 1976) by factors, such as windstorms, boating disturbances, and egg depredation. Thus, if disturbances frequently occur, then a high rate of nest abandonment would be expected. Wabamun Lake and Lac Ste. Anne colonies had higher than expected proportions of empty nests, suggesting nest abandonment was high. In particular, corvids (i.e. crows and ravens) were observed depredating nests at the Wabamun Lake colony, suggesting that they were a primary cause of nest abandonment and low mean clutch sizes. Riske (1976) also identified corvids as a 
primary factor affecting reproductive success of grebes, including western grebes. The proximity to the town of Wabamun, the Wabamun Lake power plant, and adjacent lakefront cabins may be attracting corvids to the area, thus increasing the likelihood of egg depredation. The presence of anglers observed fishing close to the western grebe colonies might also cause disturbances that exacerbated the threat of depredation.

Ground nest surveys were conducted in mid to late June, consistent with the peak nesting period identified by Kristensen and Nordstrom (1979), thus reducing the likelihood that our surveys were poorly timed. In fact, Wabamun Lake was surveyed twice during the nesting season (June 20 and June 27), and had relatively low proportions of active nests and the small mean clutch sizes both times. As well, colonies within the same geographic area should have relatively similar peak nesting periods. The Isle Lake survey, for instance, appeared to be timed appropriately since they had the highest reproductive success in our survey (Table 1), and these values were similar to those reported in the literature (Forbes 1988, Herman et al. 1969, Kristensen and Nordstrom 1979, Lindvall and Low 1982, Nero 1959, and Riske 1976). Thus, the high proportion of empty nests in the Wabamun Lake and Lac Ste. Anne colonies likely represented failed nesting attempts caused by disturbances, not nests representing unlaid eggs (expected early in the nesting season) or successful hatching events (expected late in the nesting season).

The presence of healthy western grebe populations acts like a yardstick for lake ecosystem health. Western grebes, as top predators of other ecosystems, serve as an umbrella species for lake ecosystems. Since they nest in the littoral zone, which is considered a "biodiversity hotspot" of lakes, the protection of western grebes and their nesting habitat will also secure habitat for a host of fish, invertebrate, amphibian, and other avian species. However, there are strong indications that the quality of western grebe nesting habitat is being compromised by human activities, and is having a negative impact on their abundance, distribution, and reproductive success within the Stony Plain study area. Mitigative action to reduce impacts of identified threats is considered essential. Continued monitoring of western grebe population sizes, nesting locations and reproductive measures is necessary to provide the quantification of their population trends over the long-term.

\subsection{Eared Grebes}

Lakes with over 800 eared grebe nests are considered nationally important, while lakes with 300 to 800 nests are regionally important and smaller colonies are locally important (Poston et al. 1990). Given these criteria, George Lake is nationally important to eared grebes, and Oldman Lake, Lac Ste. Anne, and Isle Lake are regionally important. Overall, we determined that the regional eared grebe population is relatively large $(n=7627$ adults). A recent survey of colonial waterbirds in northwest Alberta also reported relatively high numbers of eared grebes (3386 adults; Hanneman, and Heckbert 2001). This is likely a consequence of three behavioural characteristics that distinguish them from western grebes: eared grebes can colonise small waterbodies, they regularly establish colonies in open water areas, and large proportions of their diet include aquatic invertebrates. Thus, nesting habitat and feeding requirements for eared grebes appear to be more flexible than for western grebes. This results in higher availability of suitable habitat and the ability to sustain a larger regional population, as substantiated by the findings our surveys ( 15 of 52 lakes had presence of eared grebes). Hanneman and Heckbert (2001) also reported a relatively high proportion of lakes with eared grebes ( 11 lakes; $n=36$ lakes) in northwest Alberta. If our survey were expanded to include more waterbodies less than 100 ha in size, we expect that our regional eared grebe population estimate would increase as would the number of waterbodies with populations present. 
Reproductive measures of eared grebes provide further evidence that the overall eared grebe population is relatively secure. The clutch size means (ranged from 2.2 to $2.8 \mathrm{eggs} / \mathrm{nest}$ ) and modes (ranged from two to three eggs/nest) we observed in 2001 (Table 2) were comparable to those observed in other studies. Riske (1976) reported an overall mean clutch size of 2.4 eggs/nest on Langdon Lake and Watt Lake in central Alberta, with a range of mean clutch sizes from approximately 2.3 to 2.8 eggs/nest, and an overall modal clutch size of three eggs/nest. As well, Forbes (1985) reported a mean clutch size of 2.2 eggs/nest on Duck Lake British Columbia, and Gould (1974) reported mean clutch sizes between 2.4 and 2.9 eggs/nest in California. One study in the Cariboo Region of British Columbia (McAllister 1958) reported a much higher mean clutch size of 3.5 ( $n=173$ nests in four colonies), with a range of 3.2 to 3.7 eggs/nest, as well as higher modal values of three or four eggs, than those observed in this study (Table 2). Nevertheless, the high proportion of active nests among all colonies we surveyed in 2001 indicates that few were being abandoned, and suggests surveys were conducted at or near the peak nesting period.

Although many historical eared grebe populations (Purdy et al. 1983, and Folinsbee 1989) were still present in 2001, some underwent dramatic shifts in relative abundance. Historic eared grebe populations on Romeo Lake and potentially Big Lake (Purdy et al. 1983) were no longer present in 2001, and the population on Majeau Lake declined from approximately 2554 in 1989 (Folinsbee 1989) to approximately 50 in 2001 (Table 2). Conversely, George Lake historically did not have eared grebes (Purdy et al. 1983), yet in 2001 it had the largest population in the study area (Table 2), and we discovered eared grebe populations on 12 lakes (Table 2). These fluctuations in population size and distribution tend to be fairly characteristic for eared grebes (O’Donnel and Fjeldsa 1997) and are often reflective of changing lake water levels and habitat availability from year to year (Riske 1976). As a result, eared grebe populations for a given area often rely on a network of lakes and wetlands to sustain their population over time. However, there is also evidence that cumulative human effects, similar to those that affect western grebes, are affecting eared grebes.

The Stony Plain study area has a long history of human settlement, and consequently the landscape has been significantly impacted. Since eared grebes avoid wetlands with high human disturbance (Boe 1992), they likely have already declined in abundance and distribution due to the proliferation of lakefront development, high levels of boating activity, and removal of aquatic vegetation. From the small amount of historic data that exists, we are able to highlight how human impacts can lead to eared grebe declines. For example, the loss of eared grebes inhabiting Romeo Lake coincides with the development of the County Park and boat launch. The sudden increase in boating activity would have been devastating to past eared grebe colonies due to the small size of the lake and the lack of alternative nesting areas. In addition, there are several other lakes within the study area that may have supported eared grebes in the past (e.g. Jackfish Lake and surrounding area, and Nakamun Lake), but now are highly developed and lack colonisation. In contrast, lakes or portions of lakes with little human disturbance, especially powerboat activity and shoreline development, have some of the largest eared grebe colonies (e.g. George Lake, Brock Lake, and the west basin of Lac Ste. Anne), which further supports the hypothesis of human avoidance. Lakes with minimal development and human disturbances also enables colony formation in open water areas, which may be especially important in years with reduced emergent vegetation habitat caused by lake water level fluctuations.

Although, the regional eared grebe population appears to be relatively healthy, there are indications that local populations are somewhat sensitive to habitat loss and human disturbances. Due to the presence of several lakes or portions of lakes with minimal human presence, a sizeable 
regional population still exists within the Stony Plain study area. Continued monitoring of eared grebes is necessary to further assess their status, develop a regional population trend, and verify colony fidelity to certain lakes.

\section{$\underline{5.3 \text { Review of Protocol Techniques }}$}

In contrast to surveying waterfowl, specific protocols for surveying other waterbirds, such as western and eared grebes, have not been well developed. Riske (1976) provides the best benchmark data of western grebe relative abundance on Lac Ste. Anne, yet for the most part, historical data could not be used to evaluate western and eared grebe population trends. To address this concern, we have tested, evaluated, and refined various survey techniques, which can be used for future surveys. It became clear that a single protocol could not be used prescriptively throughout the province. Unique logistical challenges associated with each waterbody, grebe population, and colony surveyed in 2001 necessitated using a suite of techniques. Overall, we found that the most effective means of locating populations and colonies of western and eared grebes involved a combination of aerial and ground surveys, which is consistent with the findings of Cottonwood Consultants Ltd. (2000). We found that air surveys are most suited for reconnaissance of large areas, and locating grebe populations and colonies. Ground surveys were best suited for achieving relative abundance estimates, measuring reproductive success, and characterising nesting habitat. A review of each protocol used in 2001 is provided below.

\subsubsection{Ground Nest Survey}

\section{Pros}

- Walking and canoe-based ground nest surveys are the most effective protocols at producing near total counts of nests. We also found that the walking ground nest surveys for western grebe colonies can successfully achieve a near total count of nests following colony abandonment. Accurate nest counts for colonies located within stands of emergent aquatic vegetation can only be achieved from walking ground nest surveys.

- Reproductive variables within the colony, important for quantifying the status of populations, can only be achieved with this survey technique. Even from the canoe, we found that a single transect through the colony consistently sampled over $10 \%$ of the nests, and quickly and effectively measured various reproductive variables.

- The breeding adult population can be approximated using this technique by doubling the nest count estimate. These adult population estimates were consistently higher than those produced by any of the other protocols.

\section{Cons}

- The primary shortcoming of this protocol is its highly intrusive nature. These surveys have the potential to reduce nesting success and cause nest abandonment by flushing adults off their nests, which in turn exposes clutches to depredation by corvids and gulls, and potential exposure to excessive heating or cooling. It was also observed that panicked nesting grebes often do not cover their eggs and accidentally dislodge eggs from nests, which further exacerbate the depredation and reproductive success issues.

- Although the ground nest survey technique produces the most variety of data, it is also one of the most time consuming protocols - only one or two colonies can be surveyed in a day, and as many as six observers are required for a single survey to minimise time spent in the colony. 
- Adult pairs may build more than one nest if disturbed, thus the indirect measure of the adult population (taken from doubling the total nest count) may overestimate the actual population size.

- Finally, western and eared grebes are asynchronous breeders and nesting dates can vary from year to year. Thus, by only conducting one survey within an active colony, it is difficult to determine whether or not clutch data are more representative of reproductive success, or timing of egg laying.

\section{Recommendations}

Since the ground nest survey is the best way to measure reproductive success this protocol is highly recommended for future surveys, but with some modifications. To diminish the negative impacts caused by the intrusive nature of this protocol, the time spent within active colonies needs to be reduced. This can be achieved by several different ways, depending on the objectives:

- A total nest count can be conducted following the nesting period in mid to late July, thus eliminating disturbance to the colony altogether. This only applies to colonies located in emergent vegetation. Habitat characterisation should also be conducted following colony abandonment.

- Several abbreviated ground surveys during the nesting season can be used to supplement the ground nest survey conducted following the nesting season. Surveying along a single transect through the centre of the colony is quick, generally requiring 15 to 30 minutes, and requires only one or two observers. As well, issues associated with asynchronous egg laying can be addressed if these transects are re-surveyed near the beginning, middle, and end of the nesting period (i.e. first week of June, third week in June, and first week in July, respectively).

- Under the condition that the survey can be conducted within 30 minutes, a total count within active colonies may be appropriate if only one ground survey is possible in a season. The number of observers used must reflect the size of the colony so as the entire colony can be surveyed using two belt transects and within the recommended timeframe. For the largest colonies encountered in 2001, six observers would be recommended. To help ensure the accuracy of the reproductive success data from this single entry into the colony, the survey should be conducted during the peak nesting period (i.e. between June 7 and June 30), when the majority of clutches have been laid and before hatching occurs.

- Initial entry into active colonies should be done slowly and quietly in order to prevent undue stress to nesting birds, prevent the likelihood of accidental egg dumping by flushed grebes, provide enough time for adults to cover their eggs with vegetation, and encourage the quick return of adults to their nests.

- All ground surveys within active colonies must avoid wet, cold, windy and excessively hot conditions.

- Eggs or nests should not be touched wherever possible to avoid leaving behind human scent and increasing the likelihood of nest depredation. The use of a stick is preferred.

- Estimating adult grebe populations by doubling the nest count estimate must be used with caution, since this is an indirect measure, it does not include non-breeding adults, and may overestimate the number of breeders (e.g. one breeding pair may build more than one nest). Observation biases associated with this survey technique should be clarified whenever publishing population data derived in this way. Nevertheless, this protocol serves as a useful index of the maximum breeding adult population, the biases of which should be relatively consistent between surveys. 


\subsubsection{Air Survey}

\section{Pros}

- The air surveys are most useful for reconnaissance of large areas and locating colonies. Colonies in open water areas are easily identified from the air, and accurate nest counts can be estimated for smaller colonies (fewer than 100 nests).

- Logistical and financial benefits of this technique are that large areas can be surveyed in short amounts of time, only one or two observers are required to conduct the surveys, and fixedwing planes and their pilots are relatively inexpensive to rent when compared to helicopters.

- Photographing colonies is worthwhile for documentation purposes, and can improve nest count estimates when photographs are taken under ideal conditions. Also, by flying several passes over colonies, nest count estimates can be improved.

- Even when colonies are not located, identifying the presence of adults on lakes is possible from the air.

- The use of a Supercub fixed-wing plane has the benefit of surveying at slower speeds and lower elevations than the Cessna 180 fixed-wing plane. Surveying with pilots specialised in flying wildlife surveys is highly beneficial for route selection, and aiding with locating eared and western grebes and their colonies. Helicopters were not tested; however, they would be most practical for surveying small areas or specific lakes with historic colonies, and would likely improve the accuracy of nest counts and quality of photographs due to their hovering ability.

\section{Cons}

- The fast speed of travel is the primary drawback that precludes accurate counts of adult grebes and nests.

- Difficulties for estimating adult western and eared grebes, especially from the air, are due to the small size of the birds, their constant diving behaviour, and clumped distributions. Young of the year are generally not detectable from the air.

- Nest counts were possible from the air, but were gross underestimates from the actual total, especially when colonies covered large areas, when nests were unevenly distributed, and/or nests were located among emergent vegetation.

- Small colonies located among emergent aquatic vegetation are usually undetectable from the air, and distinguishing nests between species in mixed colonies is not possible.

- Counting nests from photographs proved unreliable due to factors relating to light glare, flying height and angle, and colony size and distribution.

- Flying over colonies likely causes significant disturbance to the colony, especially when several passes are made at low flying altitudes (less than $75 \mathrm{~m}$ ). Helicopters likely cause more auditory, visual and wave disturbance than fixed-wing planes.

- Surveying from a Supercub as opposed to a Cessna 180 results in relatively few improvements in locating grebe populations and their colonies, and estimating their size. Reconnaissance of large areas using a helicopter is less cost effective than either type of fixedwing plane, due to substantially higher rental rates.

\section{Recommendations}

- Air surveys are most useful for locating colonies and adult populations and providing very crude (and generally considerably underestimated) counts of nests and adults. To minimise disturbance to colonies and to increase the survey area per flight, time spent estimating colony size or number of adult grebes should be minimised. 
- We recommend photographing colonies wherever possible for documentation purposes; however, the protocol would need to be significantly improved in order to achieve consistently accurate nest counts.

- To further limit observation biases, the same observers who have previous bird censusing experience should be used wherever possible.

- These surveys should be conducted between the end of May to mid June to coincide with the early stages of colony formation, thus leaving enough time to conduct ground nest surveys.

- The advantages and disadvantages of using fixed-wing planes for aerial grebe surveys tend to outweigh those of helicopters in most cases. The use of helicopter may be justified if reconnaissance is not required, and the objective is to conduct nest counts on as many known colonies within a short period of time.

- Broad scale surveys of colonial grebes would likely need to be integrated into general colonial nesting waterbird surveys as exemplified by Hanneman and Heckbert (2001), and described by the British Columbia Ministry of Environment, Lands and Parks Resource Inventory Branch (1998). Cottonwood Consultants Ltd. (2000) also support this recommendation. The addition of colonial grebes and other waterbirds to annual waterfowl surveys is another approach of monitoring broad scale trends and distributions.

\subsubsection{Meandering Shoreline Boat Survey}

\section{Pros}

- The meandering shoreline boat survey is excellent for detecting presence of adult western and eared grebes, and locating larger colonies. It has the benefit over other survey techniques of being more likely to locate colonies within stands of emergent vegetation, since the nesting grebes can be heard calling from within the stands, and the presence of loafing adults often indicates the presence of a colony nearby.

- A peripheral benefit of the meandering shoreline boat survey is that it is a suitable technique for counting other waterbirds, thus broadening its scope and improving its cost effectiveness.

\section{Cons}

- Population estimates are generally poor since the primary objective of the meandering shoreline survey is to locate grebe colonies.

- Although this protocol is primarily intended to locate colonies, smaller colonies (i.e. less than 50 nests) are easily missed.

- Only one or two lakes can be surveyed per day using this technique, therefore this technique is not as cost effective as air surveys for locating colonies.

- The search image of observers is primarily for western and eared grebes, thus the accuracy of relative abundance estimates for other species observed are often compromised.

- The slow travelling speeds, especially while canoeing, are not conducive for estimating the relative abundance of colonial grebes or other waterbirds observed.

\section{Recommendations}

- Although the cost effectiveness of the meandering shoreline boat survey can be improved by including a general waterbird survey, we recommend using this technique only in specific areas of lakes (e.g. in prime nesting habitat areas along large stands of dense bulrush) where colonies may have been missed during air surveys.

- These surveys should be conducted between the end of May to mid June to coincide with the early stages of colony formation, and thus leaving enough time to conduct ground nest surveys. 
- Future canoe-based surveys would benefit from the use of a small outboard motor. This would enable larger areas to be covered in shorter amounts of time and reduce the potential of double counting observations. The use of a hovercraft may also be suitable for lakes too shallow for motorised boats.

\subsubsection{Systematic Boat Survey}

\section{Pros}

- The systematic boat survey produces the most accurate direct count of adult western grebe populations (this was not tested on eared grebe populations) if conducted in late July when adults are mostly swimming in open water areas and not hidden within stands of emergent vegetation. These estimates were often closest to those estimates produced by doubling nest counts derived from ground nest surveys.

- Counting young of the year was made possible with this survey technique, due to the timing of the surveys following the nesting period.

\section{Cons}

- The number of young of the year counted is considered to be significantly less than the actual number, due to their small body size, and their behaviour of riding their parents' back, and regular diving.

- Only one or two larger lakes can be surveyed in a day using this technique.

\section{Recommendations}

- On large-sized lakes with western grebe populations, the systematic boat survey should be conducted to acquire a direct measure of adults, which can be used as a comparison to the indirect count derived from the ground nest survey. These population estimates should be reported as a minimum value.

- The timing of the systematic boat survey should be shortly after colony abandonment (i.e. mid to late July) when adults and young tend to spend much of their time in open water areas. However, these surveys should be conducted before grebes begin to aggregate on lakes before fall migration, which can start as early as the end of July or early August.

- Young of the year are notoriously difficult to count regardless of the survey technique used. Since the systematic boat survey produces the best index of fledgling success, we recommend that they be counted during these surveys, remembering that it will be an underestimate. Observations biases using this technique are likely relatively similar from year to year (given similar weather conditions and timing of the survey).

- Although this technique was not tested on eared grebe populations, it would likely also produce improvements over meandering shoreline boat surveys. However, canoe-based surveys would necessitate the use of an outboard motor to increase travelling speeds, or should be conducted with a hovercraft.

\subsubsection{Shoreline Telescope Survey}

\section{Pros}

- For shallow lakes with poor access, this is the only ground technique that can verify air survey results.

- This technique is best suited for road-based surveys of small waterbodies generally less than 100 ha in size. 


\section{Cons}

- This protocol is not cost effective for waterbodies generally greater than 100 ha in size since it is time consuming to access and travel between viewpoints for each lake.

- There is a relatively high potential for double counting observations between observation viewpoints, as well as missing colonies within stands of emergent vegetation.

\section{Recommendations}

- The shoreline telescope survey should be reserved only for small waterbodies (i.e. less than $100 \mathrm{ha})$ too shallow for boating and/or with no boat access.

- Timing of this survey should coincide with the peak breeding season from early June to the early July.

- This technique may be most suited for road-based surveys of small waterbodies adjacent to roads, such as the spring waterfowl surveys conducted annually by the Canadian Wildlife Service.

\subsection{MANAGEMENT IMPLICATIONS AND FUTURE DIRECTIONS}

Surveys conducted in 2001 brought to light several key management implications necessary for colonial grebe conservation within the Stony Plain study area and throughout the province, and are described below.

1) Threats to western and eared grebes are well documented, and need to be addressed if they are to maintain viable populations within the Stony Plain study area. Primary human threats that currently affect western and eared grebes include habitat loss and boating disturbances during the breeding season. Mitigation of these threats is considered a high priority, especially for western grebes. Conservation plans for specific western and eared grebe colonies should be incorporated into larger-scale management objective for entire lakes or regions. By implementing mitigative measures designed to benefit western and eared grebes, such as identifying and protecting key habitat areas, a suite of other species, including fish and waterfowl species, will also benefit.

2) Western and eared grebes require continued monitoring in order to quantify their status in Alberta. Historic data offer little perspective on annual changes of western and eared grebe distributions, population sizes, breeding locations, and reproductive measures. Continued monitoring of these variables are recommended in order to identify trends and to provide a better assessment of status. Combined air and ground surveys should be conducted annually throughout designated survey areas for an initial five-year period, in order to assess distribution, population size, and colony fidelity to certain lakes. Primary colonies should be identified in this time, and annual ground nest counts should be conducted to provide reproductive success and total nest count data. Ideally, ground nest surveys along a single transect through these colonies should occur near the beginning, middle and end of the nesting period, followed by a total nest count soon after colony abandonment. Following this initial surveying period, surveying can be scaled back to every five years, with primary colonies being surveyed every three to five years using the ground nest survey technique. Currently, western grebes have the highest priority for future monitoring.

3) Future surveys need to utilise consistent techniques. The establishment of standardised protocols, survey routes, and survey periods, is critical for analyses of long-term trends. A 
combination of aerial and ground survey techniques is recommended. This report identified and described a suite of protocols to be used as a framework for future surveys.

4) Boating restrictions need to be established in areas surrounding historic colonies. The number of boaters, size of motors, and types of water sport activities has increased dramatically within a relatively short timeframe, with no indication of a reverse trend in the future. Western and eared grebes require secluded areas for nesting, and if viable populations are to remain on lakes with a high presence of boaters, some boating restrictions need to be established. This is especially critical for western grebes, since they tend to colonise large lakes where boating activity is often significant. Koonz and Rakowski (1985) recommended a $1000 \mathrm{~m}$ buffer around colonies during the breeding season (Approximately May 15 to July 15), where boating activity is restricted. However, we feel a buffer of $250 \mathrm{~m}$ to $500 \mathrm{~m}$ depending on the size of the lake would be more realistic while still maintaining considerable protection from disturbance. Existing motorised boating restrictions on lakes, such as George Lake, should remain in place.

5) Protective designations should be established on all nesting locations. Colonies are especially vulnerable to disturbances, thus their protection should be the focus of management efforts. Considerable amounts of nesting habitat have already become non-viable due to boatrelated disturbances and emergent vegetation clearing practices. Nesting habitat requires various levels of protection to ensure the maintenance of viable grebe populations, as well as for overall lake ecosystem health. The Lac Ste. Anne and Wabamun Lake western grebe colonies and the George Lake eared grebe colonies may have importance to their respective national populations. Thus, these colonies need the most rigorous level of protection. Eared grebe colonies at Oldman Lake, Lac Ste. Anne, and Isle Lake are considered regionally important, thus also require relatively high levels of protection. By assigning provincial and/or federal designations to nationally and regionally important colonies, regulations set for these areas are enforceable and backed by legislation. Protective notations (PNT's) should be placed on all historic colonies.

6) We recommend the promotion of public awareness to help ensure local populations remain viable. Education at the local level is considered the most important way to promote the awareness of colonial grebe ecology, potential threats to their populations, and mitigative measures (e.g. boating restrictions). Informing individuals, agencies, and/or industries that own property in the vicinity of colonies is considered high priority. We recommend the use of appropriate signage at public docks and key nesting areas, as well as actively making presentations targeted at specific groups, such as cottagers, anglers, and County representatives.

7) The development of a status report, for western grebes in particular, would further address their status in Alberta and highlight appropriate management implications to mitigate population declines. The scope of this report should be province-wide, and current monitoring efforts will be beneficial toward the status evaluation. 


\subsection{SUMMARY}

1) This survey of western and eared grebes was the first of its kind in Alberta. We produced an inventory of lakes in the Stony Plain area with western and eared grebe populations and colonies, estimated population sizes at local and regional scales, and measured reproductive success for several colonies.

2) A review of historic data determined that the knowledge base for western and eared grebes is relatively poor within the Stony Plain area and throughout much of their range. The majority of historic data for both grebe species within the Stony Plain area were collected as peripheral observations from broad-based waterbird surveys. These data provide a reasonable account of population distributions for those lakes surveyed; however, relative abundance, population trends, and colony location data are limited.

3) Western grebes appear to be threatened both regionally and locally, and their population shows evidence of decline. Although the adult western grebe population in the study area was sizeable $(n=2570)$, nearly all western grebes inhabited only three lakes (Lac Ste. Anne, Wabamun Lake, and Isle Lake), making them vulnerable to declines from disturbances at the local scale. Small populations on Lac La Nonne and Thunder Lake may represent declines of historically larger populations. Very few other lakes in the study area meet western grebe habitat requirements, thus precluding their colonisation. Nesting was confirmed on Lac Ste. Anne, Wabamun Lake, and Isle Lake, but the overall mean clutch size was low (2.3 eggs/nest), as was the proportion of active nests ( $34 \%)$. These signs suggest that local populations are being negatively impacted by the cumulative effects of habitat loss, boating disturbance, water level declines, nest depredation, angling pressure, and industrial development. Although the Wabamun Lake population was sizeable, it appeared to be the most threatened as a result of these cumulative effects, because it had the lowest mean clutch size, lowest proportion of active nests, and most evidence of nest depredation. Furthermore, inherently low recruitment rates compound impacts of cumulative effects.

4) Eared grebes are abundant regionally, but local populations are sensitive to human impacts. In 2001, a large population size was estimated, including a total of 7627 adults inhabiting 15 lakes, with nesting confirmed on 10 lakes. The largest colonies were observed on George Lake, Oldman Lake, Lac Ste. Anne, Isle Lake, and Brock Lake. Clutch sizes for eared grebes ranged between 2.2 and 2.8 , while $88 \%$ of nests were active, which was within natural variation. Locally, eared grebes share the same vulnerabilities as western grebes, and as such, human threats (i.e. habitat loss and boating disturbances) appear to be so significant on several lakes that they are preventing eared grebe colonisation. Nevertheless, eared grebes are able to mitigate against some of these threats regionally due to their habitat flexibility, which increases the availability of suitable habitat.

5) The ground nest survey is the most effective surveying technique for inventorying nests and determining clutch sizes. Data from these surveys provide near total nest counts, and a doubling these values provides an indirect measure of the breeding adult population. Furthermore, by surveying directly within the colony, reproductive success data (e.g. clutch sizes, percentage of active nests, and depredation rates) and habitat data (e.g. vegetation characterisation, colony dimensions, and water depth) can easily be gathered. Reproductive measures offer considerable quantitative evidence for population status assessments. 
However, we recommend several modifications to mitigate the invasive nature of this technique.

6) Air surveys are most useful for locating colonies within large areas, but tend to underestimate relative abundance of adults and nests. Limitations to this survey technique are largely associated with observation biases caused by the speed of travel. Especially for large survey areas, this technique can be combined with other surveys, such as a general colonial waterbird survey or waterfowl surveys, to broaden its scope. Photographing colonies is appropriate for documenting colonies, but counting nests from the photos rarely produces reasonable nest count estimates due to inconsistencies of photograph quality. A combined aerial and ground survey approach is the most effective strategy for colonial grebes.

7) Meandering shoreline boat surveys are most useful for locating colonies; however, relative abundance estimates for nests and adults are poor. Numerous observation biases are associated with counts of adults, since a large proportion of adults are hidden within colonies, and the slow travelling speeds do not keep up with the high mobility of adults swimming in open water areas. However, a secondary benefit of this survey is that a general waterbird survey can be added to the protocol, thus broadening its scope.

8) The systematic boat survey, with its specific objective to census adult western and eared grebe populations, is the most effective technique for directly estimating adult populations. Many of the observation biases associated with the meandering shoreline boat survey are accounted for using this technique (e.g. faster travelling speeds reduce the likelihood of double counting adults swimming in open water areas). This technique can also produce relative abundance estimates for young of the year, and provide an index of fledgling success.

9) The use of the shoreline telescope method should be limited to small lakes that are too shallow for boating and/or have poor access. This technique may be most suited for roadbased surveys of small waterbodies adjacent to roads, such as the spring waterfowl surveys conducted annually by the Canadian Wildlife Service. The primary drawbacks of this technique are its limited coverage and observation biases.

10) The use of the protocols outlined in this report should serve as the framework for future surveys. The use of standardised protocols in future surveys will enable the development of population trends, but the choice of protocols used will depend on the primary objectives as well as logistical and financial constraints.

11) Western and eared grebes are excellent indicators of littoral habitat quality and human disturbance levels; thus, their protection will have positive effects on a suite of other species. Healthy populations of western and eared grebes are indicative of lakes with an abundance of fish and aquatic invertebrates, availability of intact littoral habitat, and the availability of sheltered areas (e.g. bays) protected from wind and human disturbances. Furthermore, by protecting western and eared grebes and their habitat, many other avian, fish, amphibian, and invertebrate species will benefit. 


\subsection{LITERATURE CITED}

Alberta Environmental Protection. 1994a. Natural Regions of Alberta: Summary. Alberta Environmental Protection. Edmonton, AB. 18 pp.

Alberta Environmental Protection. 1994b. About Public Lands. Alberta Environmental Protection. Agriculture Food and Rural Development. Edmonton, AB. 4 pp.

Alberta Sustainable Resource Development. 2001. The general status of Alberta wild species, 2000. Alberta Environment/Alberta Sustainable Resource Development. Edmonton, AB. $46 \mathrm{pp}$.

Baicich, P. J. and C. J. O. Harrison. 1997. A guide to the nests, eggs, and nestlings of North American Birds. Second edition. Academic Press. San Diego, CA, USA. 347 pp.

Boe, J. S. 1992. Wetland selection by eared grebes Podiceps nigricollis, in Minnesota. Canadian Field Naturalist 106:480-488.

Breault, A.M., K. M. Cheng, and J-P. L. Savard. 1988. Distribution and abundance of eared grebes (Podiceps nigricollis) in British Colombia. Technical Series No 51. Canadian Wildlife Service, Pacific Yukon Region, British Columbia. 87 pp.

Burger, A. E. 1997. Status of western grebe in British Columbia. Ministry of Environment, Lands and Parks. Wildlife Branch. Victoria, BC. 30 pp.

Cottonwood Consultants Ltd. 2000. American white pelican, California gull, Caspian tern, double-crested cormorant, great blue heron, and ring-billed gull colony surveys - Alberta 1998. Volume 1. Cottonwood Consultants Ltd. Calgary, AB. 167 pp.

Eichhorst, B. A. 1992. An analysis of western grebe banding and data recovery. North American Bird Bander 17(3): 108-115.

Feerer, J. L. and R.L. Garrett. 1977. Potential western grebe extinction on California Lakes. Cal.Neva. Wildl. Trans. 80-89.

Folinsbee, J. 1989. Wildlife surveys of selected Edmonton area lakes (Majeau, Nakamun, Wabamun, and Wakomao) July 1989. Edmonton, AB. 49 pp.

Forbes, S. 1988. Western grebe nesting in British Columbia. The Murrelet 69(1):28-33.

Forbes, S. 1985. Nesting of eared grebes at Duck Lake, near Creston, British Columbia. The Murrelet 66:22-21.

Gould, G. E. 1974. Breeding success of piscivorous birds at Eagle Lake, California, M.Sc. thesis, Humbolt State University, Arcata, California.

Hanneman, M. and M. Heckbert. 2001. Colonial Nesting Waterbird Survey in the Northwest Boreal Region - 2000. Alberta Sustainable Resource Development, Fisheries and Wildlife Management Division, Alberta Species at Risk Report No. 7, Edmonton, AB. 25 pp. 
Herman S. G., R. L. Garrett, and R. L. Rudd. 1969. Pesticides and the western grebe: A study of pesticide survival and trophic concentration at Clear Lake, Lake County, California. pp. 2455. In M. W. Miller and G. G. Berg (eds.). 1969. Chemical Fallout: Current Research.

Charles C. Thomas, Springfield, IL.

Koonz W. H. and P. W. Rakowski. 1985. Status of colonial waterbirds nesting in southern Manitoba. Canadian Field-Naturalist 99(1): 19-29.

Kristensen, J., and W. R. Nordstrom. 1979. Western grebe colony, Cold Lake. Provincial parks Division, Alberta Recreation, Parks and Wildlife. 47 pp.

Lindvall, M. L., and J. B. Low. 1982. Nesting ecology and production of western grebes at Bear River Migratory Bird Refuge, Utah. Condor 84:66-70.

McAllister, N. 1958. Courtship, hostile behaviour, nest establishment and egg laying in the eared grebe (Podiceps caspicus). Auk 75: 290-311.

Ministry of Environment, Lands and Parks Resource Inventory Branch. 1998. Inventory methods for colonial-nesting freshwater birds: eared grebe, red-necked grebe, western grebe, American white pelican and great blue heron. Standards for components of British Columbia's biodiversity no. 8. Province of British Columbia, Resources Inventory Committee. Victoria, BC. ISBN 0-7726-3472-6.

Mitchell, P., and E. Prepas (eds.). 1990. Atlas of Alberta lakes. University of Alberta Press. Edmonton, AB. 675 pp.

Nero, R. W. 1959. Western Grebe Colony. Nat. Hist. 68:291-295.

Nuechterlein, G. L. 1975. Nesting ecology of western grebes on the Delta Marsh, Manitoba. Unpub. M.Sc. Thesis, Colorado State University, Denver. CO. 101 pp.

O'Donnel, C. and J. Fjeldsa (compilers).1997. Grebes - Status survey and conservation action plan. IUCN/SSC Grebe Specialist Group. IUCN. Gland, Switzerland and Cambridge, UK. vii +59 pp.

Poston, B., D. M. Ealey, P. S. Taylor, and G. B. McKeating. Priority migratory bird habitats of Canada's prairie provinces. Minister of Supply and Services Canada. Edmonton, AB. 107 $\mathrm{pp}$.

Public Lands. 2001. About public lands. http://www.agric.gov.ab.ca/publiclands/publan19a.html.

Purdy, R.O., D.C. Parkyn, and J.D. Folinsbee. 1983. Wildlife surveys of selected Edmonton area lakes June-July 1982. Unpub. Rep. Alberta Energy and Natural Resources, Fish and Wildlife Division. 139 pp.

Riske, M. E. 1976. Environmental and human impacts upon grebes breeding in central Alberta. $\mathrm{PhD}$. Thesis, University of Calgary. Calgary, AB. $482 \mathrm{pp}$. 
Semenchuck, G. P (ed.). 1992. The atlas of breeding birds of Alberta. Federation of Alberta Naturalists. Edmonton, AB. 391 pp.

Short, H. L. 1984. Habitat suitability index models: Western grebe. U.S Fish and Wildlife Service. Fort Collins CO. FWS/OBS-82/10.69. 20 pp. 
9.0 APPENDICES 


\section{Appendix 1 Map of Alberta, the Stony Plain study area and distribution of grebe colonies}

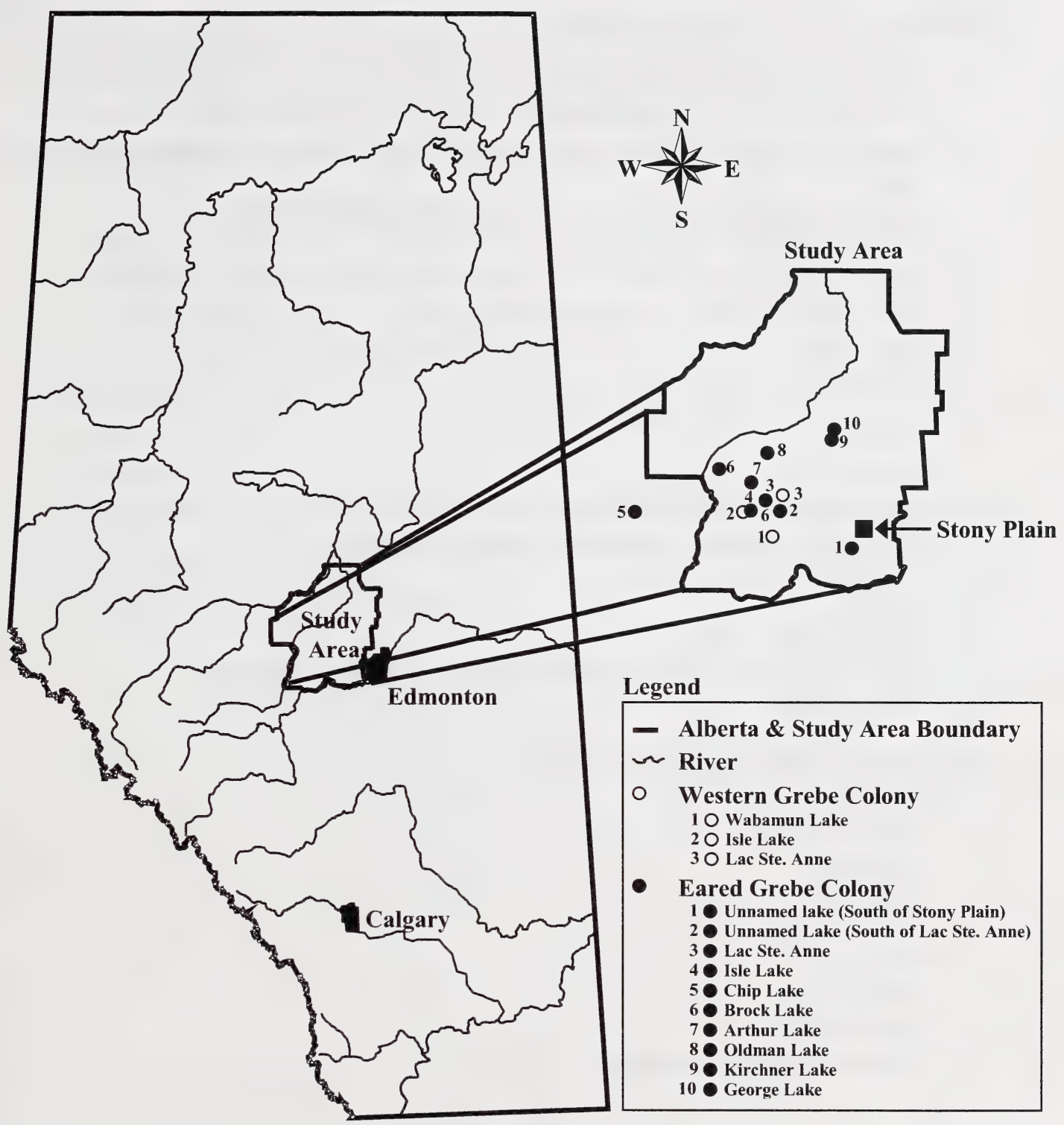




\section{Appendix 2 Equipment list}

Equipment List (per field team of two):

- Appropriate maps (air photos, access maps, county maps, topography maps)

- Bags (garbage and/or dry bags to protect field equipment from water)

- Binoculars (7-10X; 1 per individual)

- Buoys (20; made from fluorescent closed-cell foam attached to a small bag filled with sand)

- Large re-sealable bags (protect data sheets and maps from water)

- Camera (with film, extra batteries)

- Clip board (1 per individual)

- Data sheets (on water resistant paper) and binder

- Duct tape

- Felt markers

- Field guides for birds and aquatic plants

- First aid kit

- Flagging tape

- GPS unit (with extra AA batteries)

- Maps (e.g., road maps, topographic maps, access maps)

- Map rulers of various scales

- Pencils

- Spotting scope (>20X)

- Survival kit (flares, survival blanket, reflector, waterproof matches)

- Thermometer

Recommended Field Gear (per individual):

- Backpack

- Bug nets/jacket

- Compass

- Hip waders

- Multi-tool knife

- Rain gear

- Rubber boots

- Sunscreen

- Warm clothes, hat, sunglasses 
Appendix 2 (Cont.) Equipment list

\section{Boat Equipment (per vessel):}

- Anchor with a minimum of 50' of rope

- Bow rope

- Communication equipment (e.g. radio or mobile phone)

- Fire extinguisher

- First aid kit

- Floodlight or waterproof flashlight

- Lifejacket (per person)

- Navigation aid (compass, GPS, and maps)

- Navigation lights

- Passive radar reflectors for non-metallic watercraft (e.g. fibreglass canoe)

- Spare gasoline container

- Spare paddle

- Spare rope

- Survival kit

- Throwing device (either an approved buoyant heaving line or lifebuoy with $15 \mathrm{~m}$ of line)

- Tool kit

- Water bailer

- Whistle (attached to each lifejacket) 


\section{Waterbird Survey Observations}

Lake:

Transect \#

Transect Start UTM Location:

Transect End UTM Location:

Air Temp. $\left({ }^{\circ} \mathrm{C}\right)$ :

Visibility Index ${ }^{1}$ :

'Visibility Index: $P=$ Poor; $S=$ Satisfactory; $G=$ Good

${ }^{2}$ Wind Speed: C = Calm (0-2km/hr); S = Slight $(3-12 \mathrm{~km} / \mathrm{hr}) ; M=$ Moderate $(13-29 \mathrm{~km} / \mathrm{hr}) ; \mathrm{G}=$ Gusty $(>30 \mathrm{~km} / \mathrm{hr})$

${ }^{3}$ Wind Direction: $N=$ North; NE =Northeast; $E=$ East; $S E=$ Southeast; $S=$ South; $S W=$ Southwest; $W=$ West; $N W=$ Northwest; $X=$ No Wind

"Water Surface: $C=$ Calm; R = Ripples $(1-5 \mathrm{~cm}) ; \mathrm{SW}=$ Small Waves $(6-10 \mathrm{~cm})$; Medium Waves $(11-20 \mathrm{~cm}) ; \mathrm{LW}=$ Large Wave $(>20 \mathrm{~cm})$

\begin{tabular}{|c|c|c|}
\hline Species & Numbers of Individuals & Total \\
\hline \multirow{2}{*}{ Eared Grebe } & & \\
\hline & nest count: & \\
\hline \multicolumn{3}{|c|}{ Horned Grebe } \\
\hline \multicolumn{3}{|c|}{ Pied-Billed Grebe } \\
\hline \multicolumn{3}{|c|}{ Red-Necked Grebe } \\
\hline & nest count: & \\
\hline \multicolumn{3}{|l|}{ Western Grebe } \\
\hline & nest count: & \\
\hline \multicolumn{3}{|c|}{ American Widgeon } \\
\hline \multicolumn{3}{|c|}{ Blue-Winged Teal } \\
\hline \multicolumn{3}{|c|}{ Bufflehead } \\
\hline \multicolumn{3}{|l|}{ Canvasback } \\
\hline \multicolumn{3}{|c|}{ Cinnamon Teal } \\
\hline \multicolumn{3}{|c|}{ Common Goldeneye } \\
\hline \multicolumn{3}{|l|}{ Gadwall } \\
\hline \multicolumn{3}{|c|}{ Green-Winged Teal } \\
\hline \multicolumn{3}{|c|}{ Lesser Scaup } \\
\hline \multicolumn{3}{|l|}{ Mallard } \\
\hline \multicolumn{3}{|c|}{ Northern Pintail } \\
\hline \multicolumn{3}{|c|}{ Northern Shoveller } \\
\hline \multicolumn{3}{|c|}{ Redhead } \\
\hline \multicolumn{3}{|c|}{ Ring-Necked Duck } \\
\hline \multicolumn{3}{|c|}{ Ruddy Duck } \\
\hline \multicolumn{3}{|c|}{ White-Winged Scoter } \\
\hline \multicolumn{3}{|l|}{ Black Tern } \\
\hline \multicolumn{3}{|l|}{ Common Tern } \\
\hline Forster's Tern & & \\
\hline
\end{tabular}

Wind Speed ${ }^{2}:$ Water Surface ${ }^{4}$ :

Wind Direction ${ }^{3}$ :__ Cloud Cover (\%):

Water Surface ${ }^{4}$ :
Cloud Cover $(\%)$
Date:_Crew:____ Survey Method:

Transect Start Time:

Transect End Time: 
Appendix 3.1 (cont.) Blank Waterbird Data Sheet (Meandering Shoreline Boat Survey)

\section{Waterbird Survey Observations}

Lake:

Transect \#

Species

Bonaparte's Gull

California Gull

Franklin's Gull

Herring Gull

Ring-Billed Gull

American White Pelican

American Bittern

American Coot

Canada Goose

Common Loon

Common Merganser

Double Crested Cormorant

Great Blue Heron

Trumpeter Swan

American Avocet

Common Snipe

Greater Yellowlegs

Killdeer

Marbled Godwit

Lesser Yellowlegs

Long-Billed Curlew

Long-Billed Marsh Wren

Spotted Sandpiper

Wilson's Phalarope

Willet

American Crow

Black-Billed Magpie

Common Raven

Kingfisher

Red-Winged Blackbird

Yellow-Headed Blackbird

Bald Eagle

Golden Eagle

Goshawk

Marsh Hawk

Osprey

Red-Tailed Hawk
(Set 2)

Date:

Crew:

Transect Descriptor Name:

Number of Individuals

Total 


\section{Ground Nest Survey}

Date:

Lake:

Species:

Colony Location (UTM):
Crew:

Colony Descriptor Name:

Estimated \# of Adults:

\begin{tabular}{|c|c|c|}
\hline Time Start & Wind Speed $^{2}$ & Emergent Veg. Spp ${ }^{5}$ \\
\hline Time End & Wind Direction ${ }^{3}$ & Backshore Veg. Spp ${ }^{6}$ \\
\hline Air Temp. $\left({ }^{\circ} \mathrm{C}\right)$ & Water Surface ${ }^{4}$ & Mean Water Depth (m) \\
\hline Cloud Cover (\%) & Island (I), Shore (S), & Colony Width (m) \\
\hline Visibility Index & or Gravel Bar (G) & Colony Length (m) \\
\hline
\end{tabular}

Visibility Index: $P=$ Poor; $S=$ Satisfactory; $\mathrm{G}=\mathrm{Good}$

${ }^{2}$ Wind Speed: $C=$ Calm $(0-2 \mathrm{~km} / \mathrm{hr}) ; S=$ Slight $(3-12 \mathrm{~km} / \mathrm{hr}) ; M=$ Moderate $(13-29 \mathrm{~km} / \mathrm{hr}) ; G=$ Gusty $(>30 \mathrm{~km} / \mathrm{hr})$

${ }^{3}$ Wind Direction: $N=$ North; $N E=$ Northeast; $E=$ East; $S E=$ Southeast; $S=$ South; $S W=$ Southwest $W=$ West; $N W=$ Northwest; $X=$ No Wind

"Water Surface: C = Calm; R = Ripples $(1-5 \mathrm{~cm}) ; \mathrm{SW}=$ Small Waves $(6-10 \mathrm{~cm})$; Medium Waves $(11-20 \mathrm{~cm}) ; \mathrm{LW}=$ Large Wave $(>20 \mathrm{~cm})$

${ }^{5}$ Emergent Vegetation Species: $\mathrm{C}=$ Carex; $\mathrm{G}=$ Grass; $\mathrm{N}=$ Nuphar, $\mathrm{O}=\mathrm{Other} ; \mathrm{P}=$ Phragmites; $\mathrm{S}=$ Scirpus spp.; $\mathrm{T}=$ Typha; $\mathrm{X}=$ No Vegetation

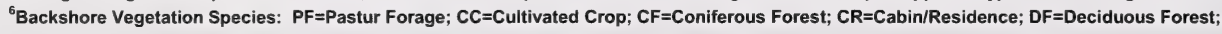

\begin{tabular}{|c|c|c|c|c|c|c|c|}
\hline Nest \# & Clutch Size & Nest \# & Clutch Size & Nest \# & Clutch Size & Nest \# & Clutch Size \\
\hline 1 & & 25 & & 49 & & 73 & \\
\hline 2 & & 26 & & 50 & & 74 & \\
\hline 3 & & 27 & & 51 & & 75 & \\
\hline 4 & & 28 & & 52 & & 76 & \\
\hline 5 & & 29 & & 53 & & 77 & \\
\hline 6 & & 30 & & 54 & & 78 & \\
\hline 7 & & 31 & & 55 & & 79 & \\
\hline 8 & & 32 & & 56 & & 80 & \\
\hline 9 & & 33 & & 57 & & 81 & \\
\hline 10 & & 34 & & 58 & & 82 & \\
\hline 11 & & 35 & & 59 & & 83 & \\
\hline 12 & & 36 & & 60 & & 84 & \\
\hline 13 & & 37 & & 61 & & 85 & \\
\hline 14 & & 38 & & 62 & & 86 & \\
\hline 15 & & 39 & & 63 & & 87 & \\
\hline 16 & & 40 & & 64 & & 88 & \\
\hline 17 & & 41 & & 65 & & 89 & \\
\hline 18 & & 42 & & 66 & & 90 & \\
\hline 19 & & 43 & & 67 & & 91 & \\
\hline 20 & & 44 & & 68 & & 92 & \\
\hline 21 & & 45 & & 69 & & 93 & \\
\hline 22 & & 46 & & 70 & & 94 & \\
\hline 23 & & 47 & & 71 & & 95 & \\
\hline 24 & & 48 & & 72 & & 96 & \\
\hline
\end{tabular}

Note: $\mathrm{A}=\mathrm{Abandoned}$ Nest, $\mathrm{C}=$ Chick, $\mathrm{F}=$ Fragments of Shells, $\mathrm{P}=$ Predation 
Appendix 3.2 (Cont.) Blank Ground Nest Survey Data Sheet

Ground Nest Survey

Date:

Lake:

Colony Descriptor Name:

Species:

\begin{tabular}{|c|c|c|c|c|c|c|c|}
\hline Nest \# & Clutch Size & Nest \# & Clutch Size & Nest \# & Clutch Size & Nest \# & Clutch Size \\
\hline 97 & & 141 & & 176 & & 211 & \\
\hline 98 & & 142 & & 177 & & 212 & \\
\hline 99 & & 143 & & 178 & & 213 & \\
\hline 100 & & 144 & & 179 & & 214 & \\
\hline 101 & & 145 & & 180 & & 215 & \\
\hline 102 & & 146 & & 181 & & 216 & \\
\hline 103 & & 147 & & 182 & & 217 & \\
\hline 104 & & 148 & & 183 & & 218 & \\
\hline 105 & & 149 & & 184 & & 219 & \\
\hline 106 & & 150 & & 185 & & 220 & \\
\hline 107 & & 151 & & 186 & & 221 & \\
\hline 108 & & 152 & & 187 & & 222 & \\
\hline 109 & & 153 & & 188 & & 223 & \\
\hline 110 & & 154 & & 189 & & 224 & \\
\hline 111 & & 155 & & 190 & & 225 & \\
\hline 112 & & 156 & & 191 & & 226 & \\
\hline 113 & & 157 & & 192 & & 227 & \\
\hline 114 & & 158 & & 193 & & 228 & \\
\hline 115 & & 159 & & 194 & & 229 & \\
\hline 116 & & 160 & & 195 & & 230 & \\
\hline 117 & & 161 & & 196 & & 231 & \\
\hline 118 & & 162 & & 197 & & 232 & \\
\hline 119 & & 163 & & 198 & & 233 & \\
\hline 120 & & 164 & & 199 & & 234 & \\
\hline 121 & & 165 & & 200 & & 235 & \\
\hline 122 & & 166 & & 201 & & 236 & \\
\hline 123 & & 167 & & 202 & & 237 & \\
\hline 124 & & 168 & & 203 & & 238 & \\
\hline 125 & & 169 & & 204 & & 239 & \\
\hline 126 & & 170 & & 205 & & 240 & \\
\hline 127 & & 171 & & 206 & & 241 & \\
\hline 128 & & 172 & & 207 & & 242 & \\
\hline 129 & & 173 & & 208 & & 243 & \\
\hline 130 & & 174 & & 209 & & 244 & \\
\hline 140 & & 175 & & 210 & & 245 & \\
\hline
\end{tabular}

Note: $A=A$ bandoned Nest, $C=$ Chick, $F=$ Fragments of Shells, $P=$ Predation 
을
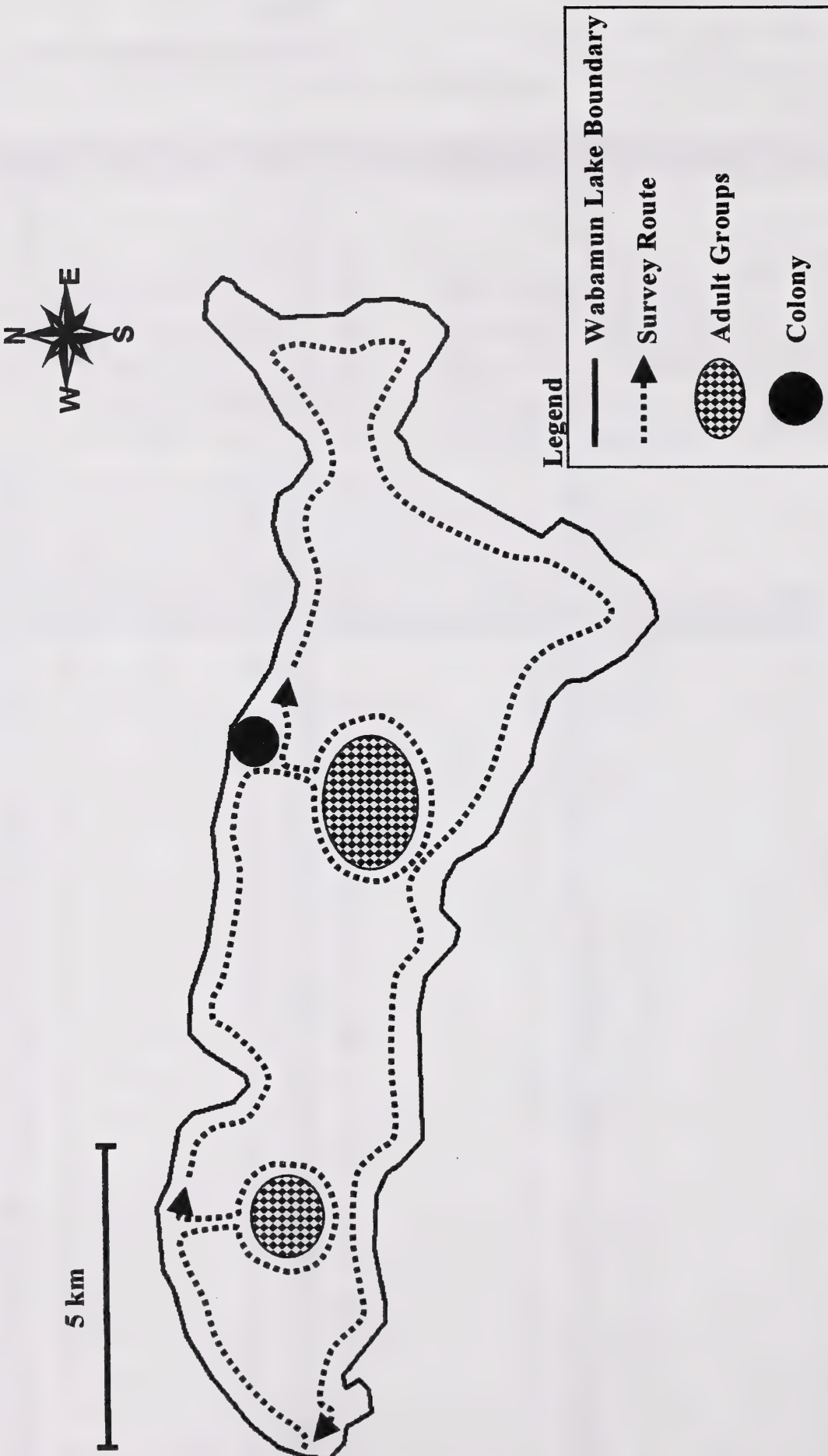
है
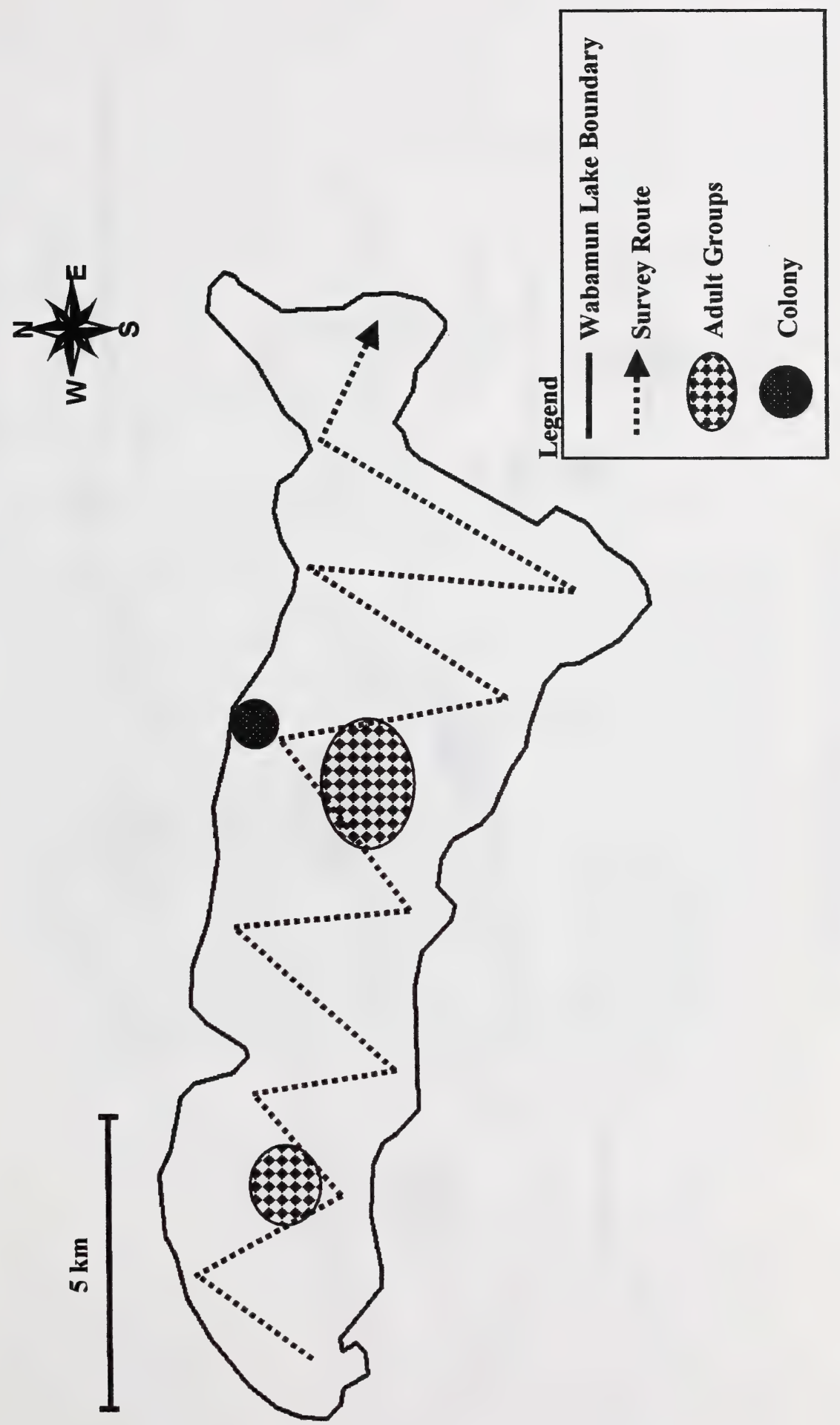
है

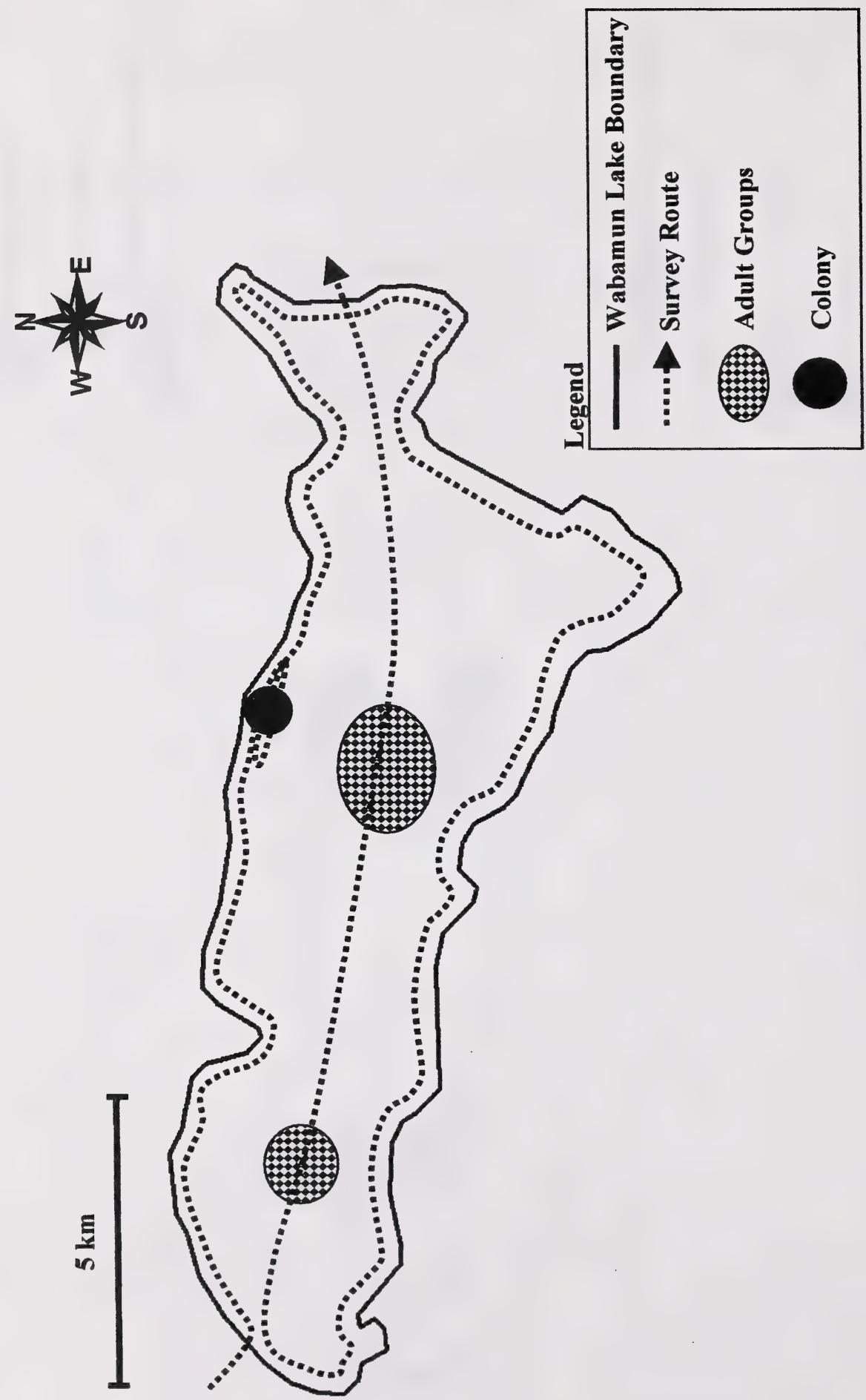




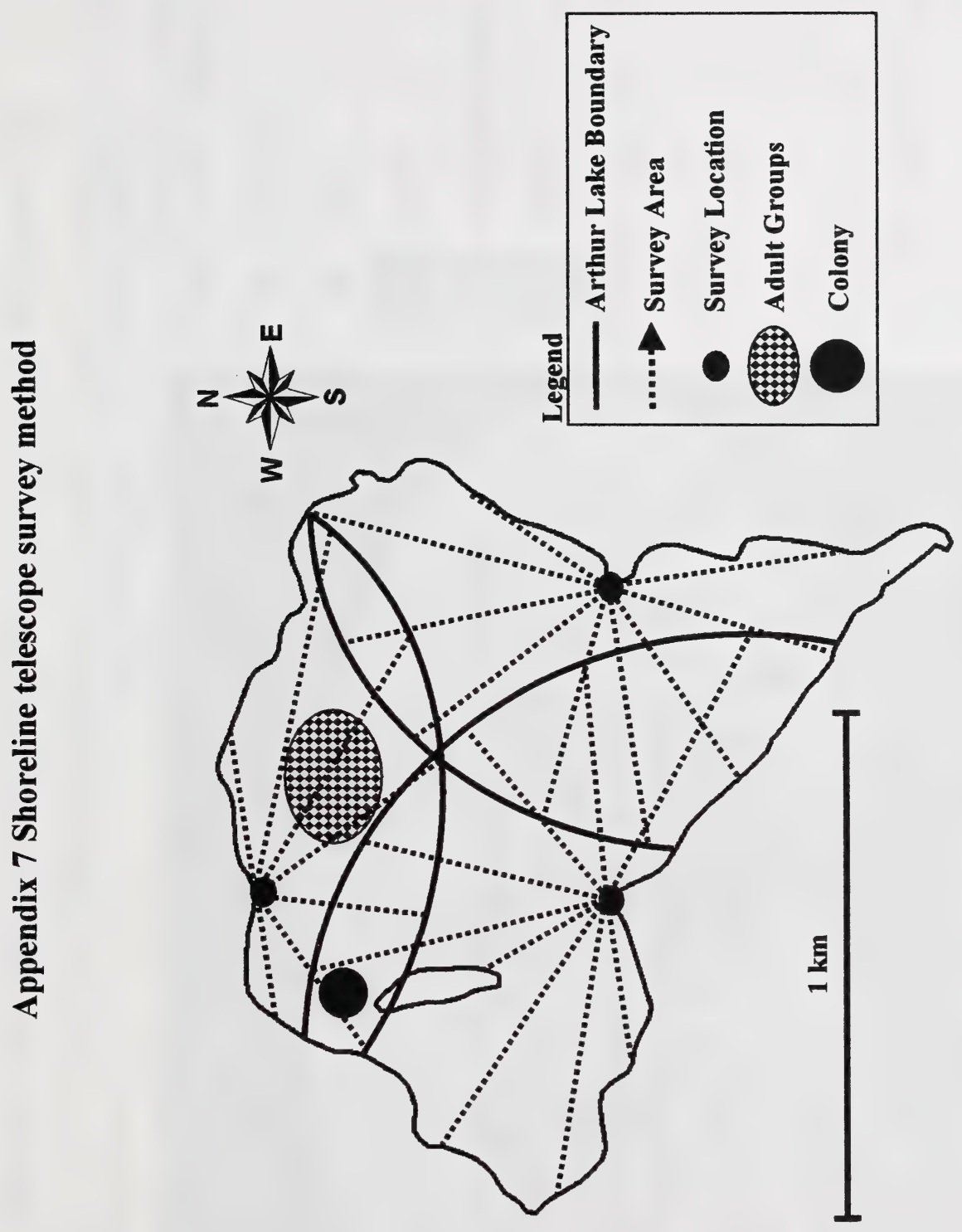



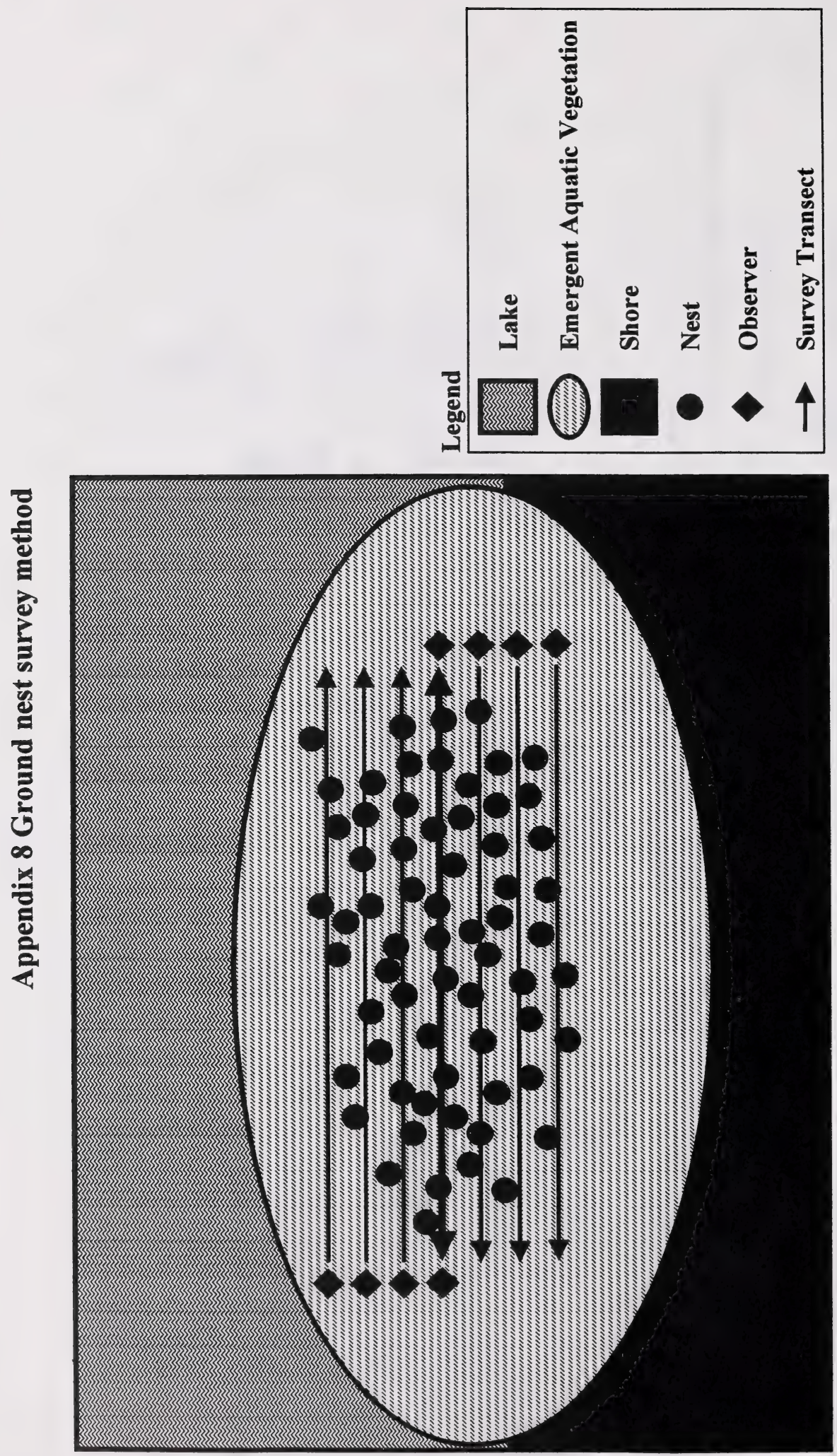


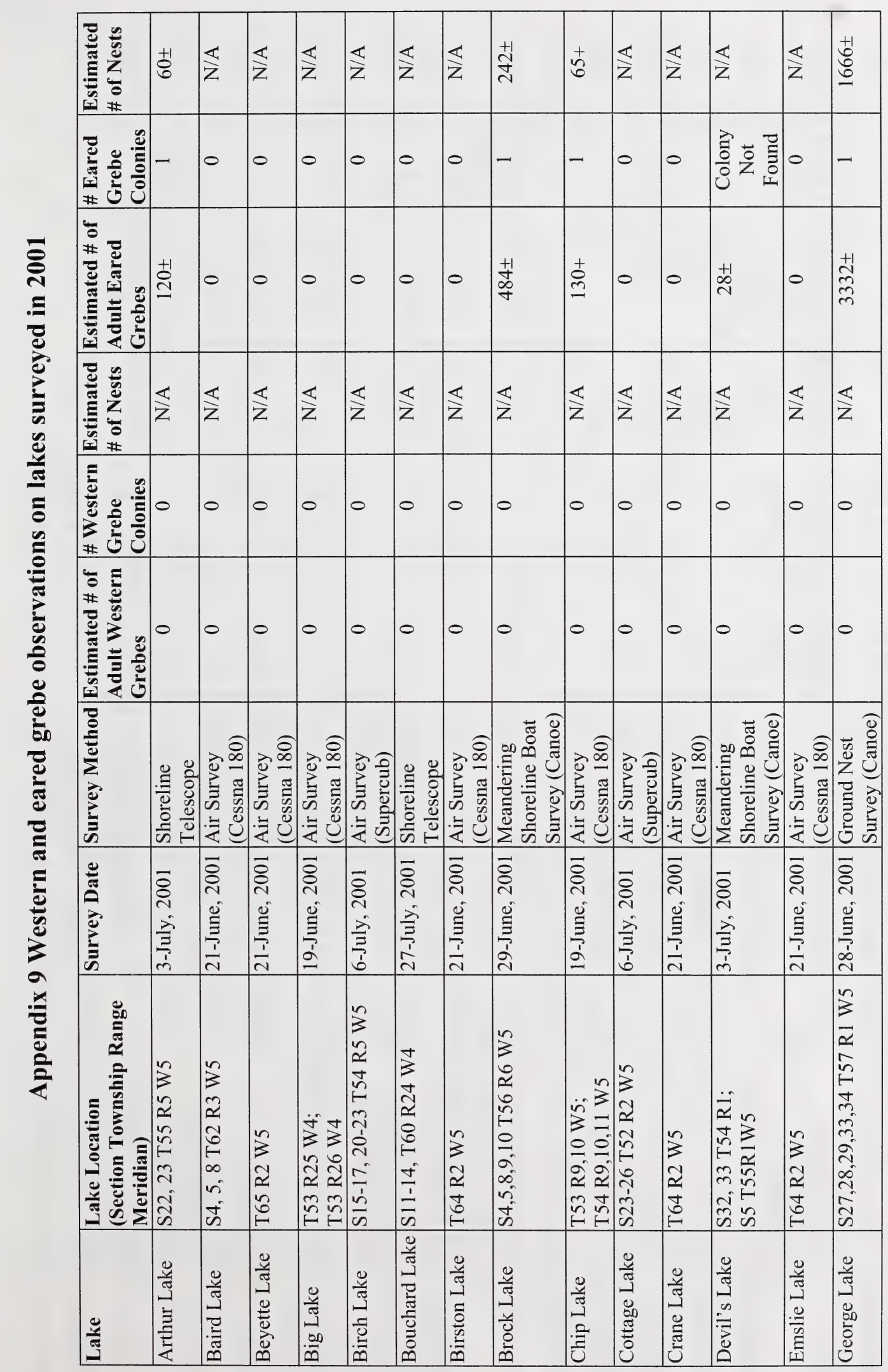




\begin{tabular}{|c|c|c|c|c|c|c|c|c|c|c|c|c|c|}
\hline 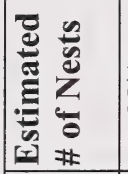 & $\frac{\mathbb{Z}}{\mathrm{z}}$ & $\frac{\varangle}{z}$ & $\frac{\ll}{\mathrm{z}}$ & $\frac{\Delta}{\mathrm{z}}$ & $\frac{\varangle}{\mathrm{z}}$ & 趁 & $\frac{\mathbb{Z}}{\mathrm{Z}}$ & $\frac{\nwarrow}{\mathbf{z}}$ & $\frac{\mathbb{Z}}{\mathrm{Z}}$ & $\frac{\varangle}{\mathrm{z}}$ & $\frac{\mathbb{Z}}{\mathrm{z}}$ & 志 & $\frac{\varangle}{\mathrm{z}}$ \\
\hline 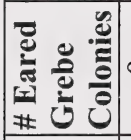 & 0 & 0 & 0 & 10 & 0 & - & 0 & 0 & 0 & 0 & 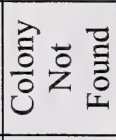 & - & 0 \\
\hline 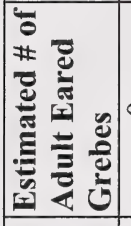 & 0 & 0 & 0 & 0 & 0 & $\stackrel{+1}{\circ}$ & 0 & 0 & 0 & 0 & $\stackrel{+1}{8}$ & 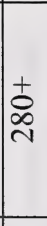 & 0 \\
\hline 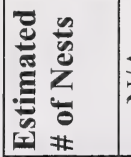 & $\frac{\mathbb{Z}}{\mathrm{z}}$ & $\frac{\varangle}{z}$ & $\frac{\ll}{\mathrm{z}}$ & $\frac{\ll}{z}$ & $\frac{\varangle}{\mathrm{z}}$ & $\stackrel{+}{2}$ & $\frac{\varangle}{\mathrm{z}}$ & $\frac{\varangle}{\mathrm{z}}$ & $\frac{\varangle}{\mathrm{z}}$ & $\frac{\ll}{\mathrm{z}}$ & $\frac{\mathbb{Z}}{\mathrm{Z}}$ & $\frac{\ll}{z}$ & $\frac{\ll}{z}$ \\
\hline 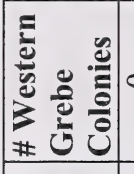 & 0 & 0 & 0 & 0 & 0 & $N$ & 0 & 0 & 10 & 0 & 0 & 0 & 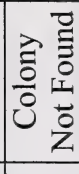 \\
\hline 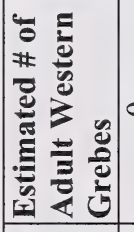 & 0 & 0 & 0 & 0 & 0 & $\stackrel{+1}{\stackrel{+}{n}}$ & 0 & 10 & 0 & 10 & 0 & 0 & $\stackrel{+1}{\stackrel{⿲}{\sim}}$ \\
\hline
\end{tabular}

\begin{tabular}{|c|c|c|c|c|c|c|c|c|c|c|c|c|c|}
\hline 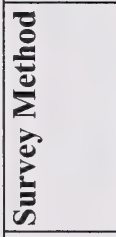 & 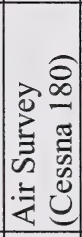 & 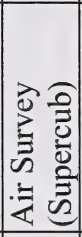 & 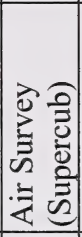 & 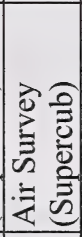 & 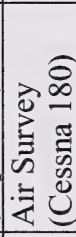 & 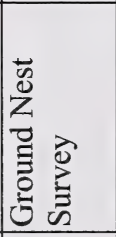 & 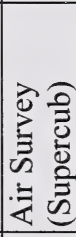 & 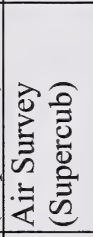 & 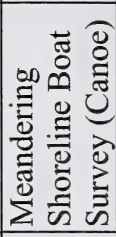 & 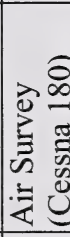 & 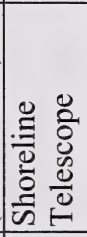 & 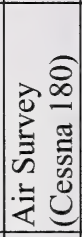 & 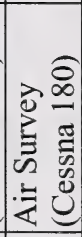 \\
\hline है & 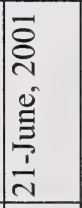 & 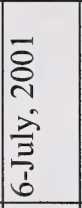 & 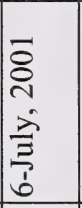 & $\begin{array}{l}\overline{8} \\
8 \\
\cdots \\
\vdots \\
\vdots \\
b \\
\end{array}$ & 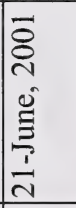 & 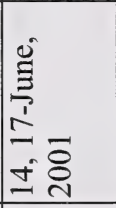 & $\begin{array}{l}\overline{5} \\
8 \\
1 \\
2 \\
\vdots \\
6 \\
6\end{array}$ & 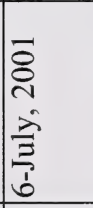 & $\begin{array}{l}\overline{8} \\
8 \\
2 \\
3 \\
\frac{1}{3} \\
\end{array}$ & $\begin{array}{l}\overline{8} \\
\tilde{N} \\
0 \\
\vdots \\
\vdots \\
\frac{1}{2} \\
\end{array}$ & $\begin{array}{l}\overline{8} \\
0 \\
2 \\
i n \\
0 \\
\vdots \\
\end{array}$ & 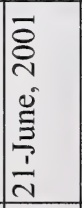 & 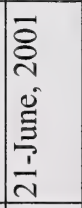 \\
\hline 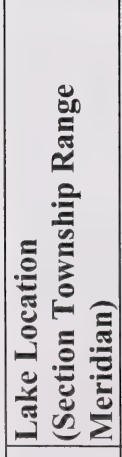 & 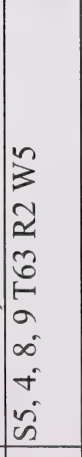 & 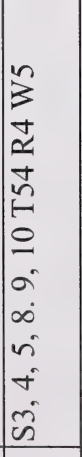 & 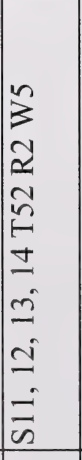 & 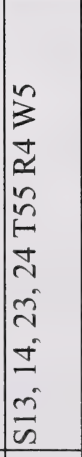 & 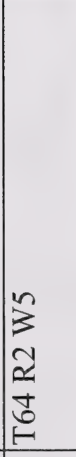 & 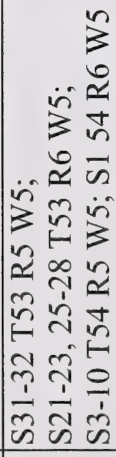 & $\begin{array}{l}n \\
3 \\
2 \\
21 \\
n \\
n \\
= \\
= \\
0 \\
0 \\
a \\
\infty \\
\infty\end{array}$ & 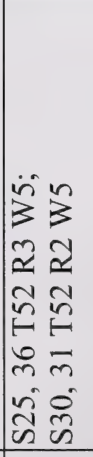 & 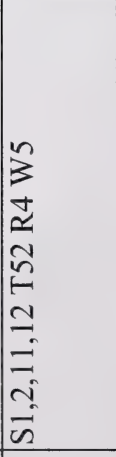 & 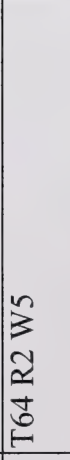 & 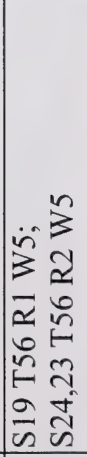 & 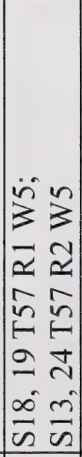 & 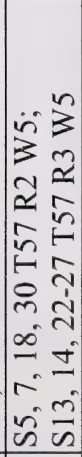 \\
\hline 疍 & 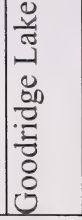 & 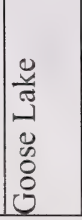 & 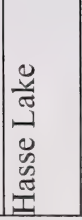 & 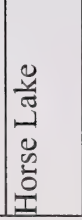 & 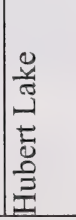 & 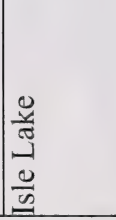 & 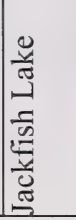 & 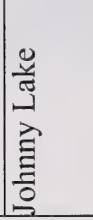 & 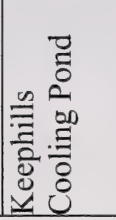 & 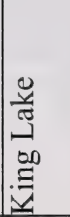 & 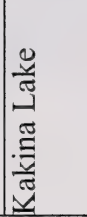 & 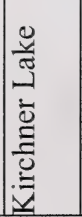 & 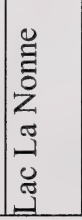 \\
\hline
\end{tabular}




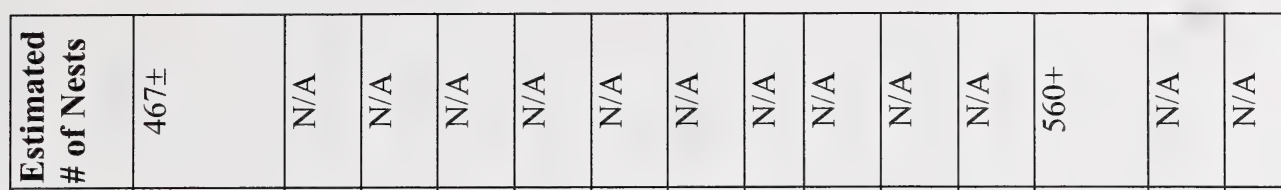

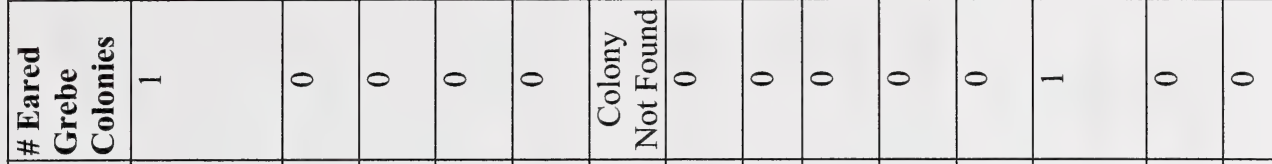

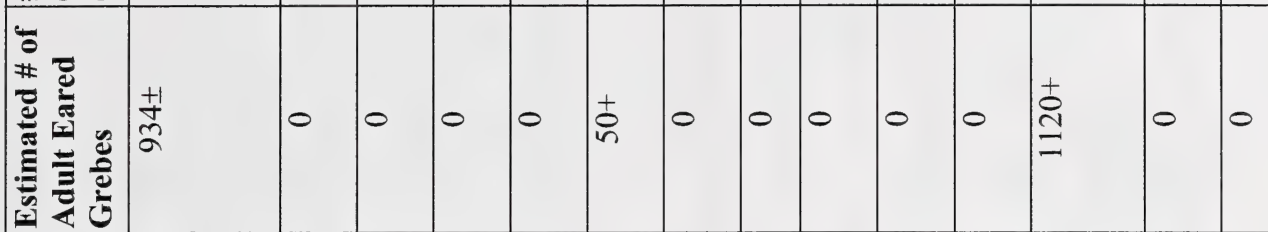

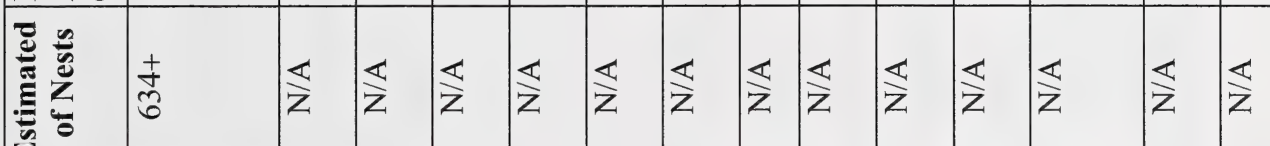

政

赔高

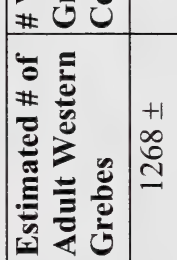

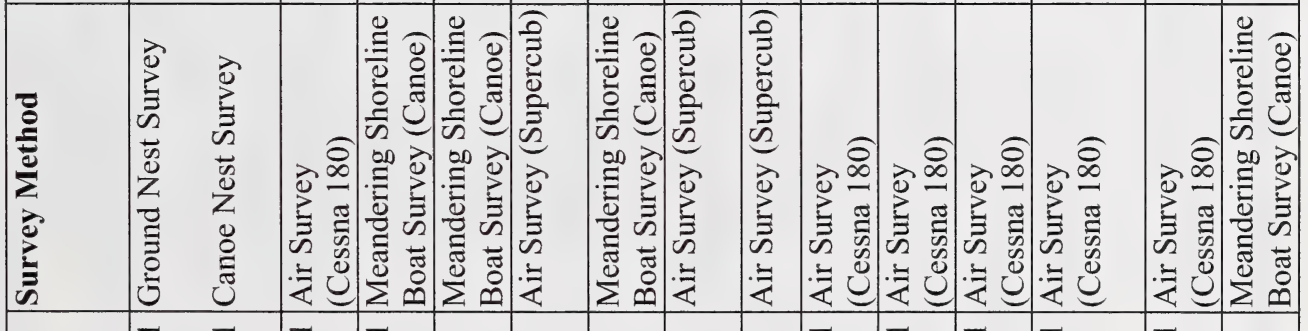

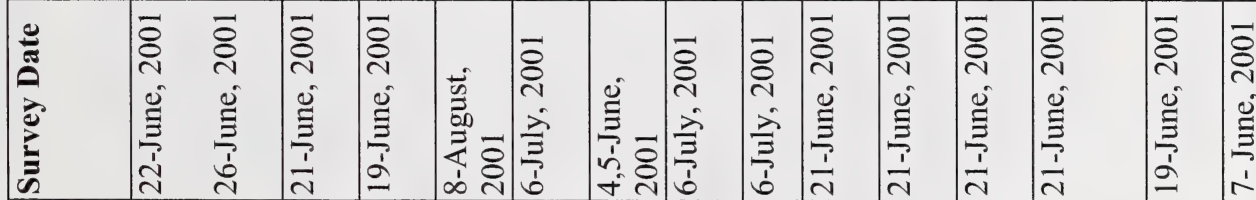

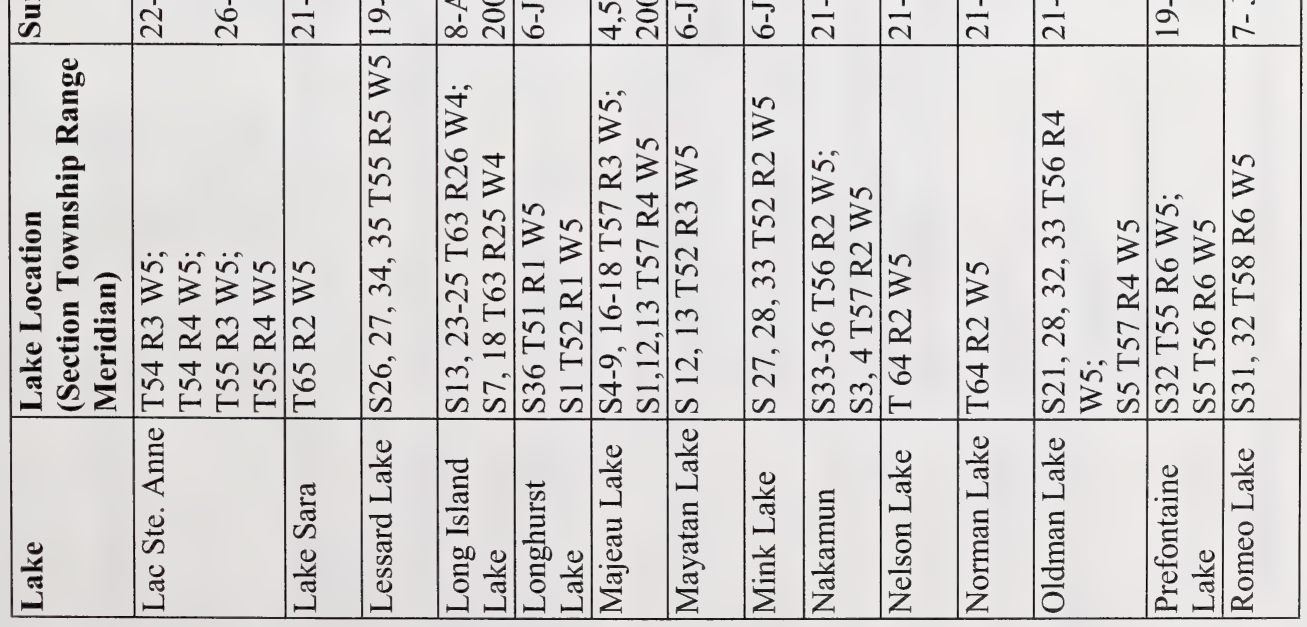




\begin{tabular}{|c|c|c|c|c|c|c|c|c|c|c|c|}
\hline 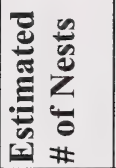 & $\frac{\mathbb{Z}}{\mathrm{z}}$ & $\frac{\pi}{z}$ & $\frac{\mathbb{Z}}{\mathrm{z}}$ & $\frac{\mathbb{Z}}{\mathrm{Z}}$ & $\frac{\mathbb{Z}}{\mathrm{Z}}$ & 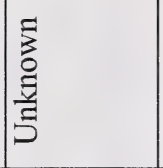 & $\frac{+1}{m}$ & +1 & $\frac{\mathbb{Z}}{\mathrm{Z}}$ & $\frac{\mathbb{Z}}{\mathrm{Z}}$ & $\frac{\mathbb{Z}}{\mathrm{Z}}$ \\
\hline 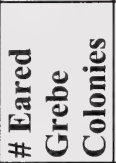 & 0 & 0 & 0 & 0 & 0 & 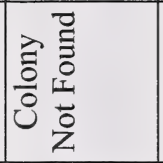 & $\sim$ & $\sim$ & 0 & 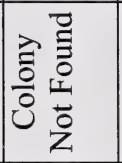 & 0 \\
\hline 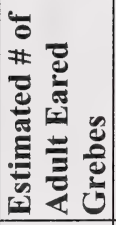 & 0 & 0 & 0 & 0 & 0 & $\stackrel{+1}{=}$ & $\stackrel{+1}{\text { đิ }}$ & $\stackrel{+1}{\stackrel{+}{\sim}}$ & 0 & $m$ & 0 \\
\hline 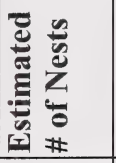 & $\frac{\mathbb{Z}}{\mathrm{z}}$ & $\frac{\mathbb{Z}}{\mathrm{z}}$ & $\frac{\mathbb{Z}}{\mathrm{z}}$ & $\frac{\nwarrow}{z}$ & $\frac{\ll}{z}$ & 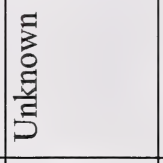 & $\frac{\nwarrow}{Z}$ & $\frac{\mathbb{Z}}{\mathrm{Z}}$ & $\begin{array}{l}+1 \\
8 \\
0 \\
n\end{array}$ & $\frac{\mathbb{Z}}{\mathrm{z}}$ & $\frac{\ll}{z}$ \\
\hline 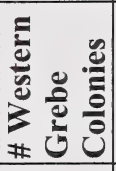 & 0 & 0 & 0 & 0 & 0 & 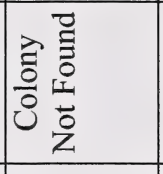 & 0 & 0 & - & 0 & 0 \\
\hline 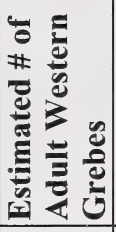 & 0 & 0 & 0 & 0 & 0 & $\stackrel{+}{m}$ & 0 & 0 & $\stackrel{+1}{\stackrel{+}{\mathbf{d}}}$ & 0 & 0 \\
\hline 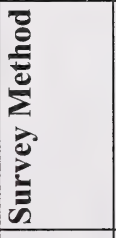 & 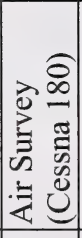 & 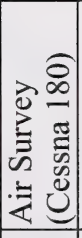 & 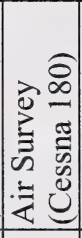 & 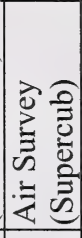 & 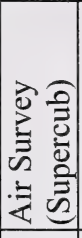 & 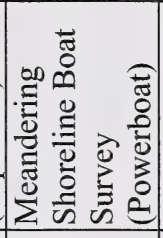 & 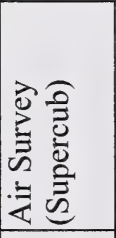 & 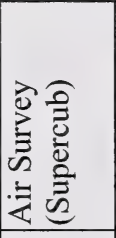 & 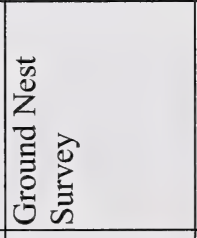 & 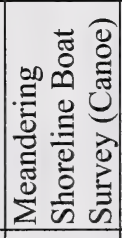 & 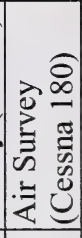 \\
\hline 营 & $\begin{array}{l}\overline{0} \\
0 \\
\sim \\
0 \\
\vdots \\
\vdots \\
0 \\
0 \\
\end{array}$ & 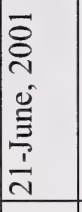 & 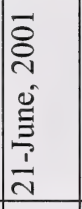 & 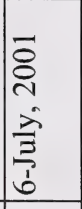 & 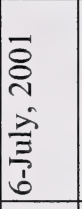 & 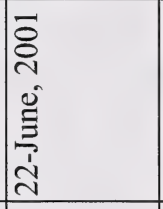 & 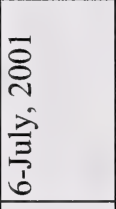 & $\begin{array}{l}\overline{8} \\
\text { N } \\
2 \\
3 \\
\vdots \\
b\end{array}$ & 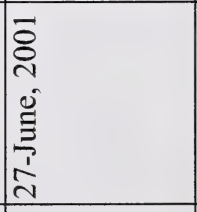 & 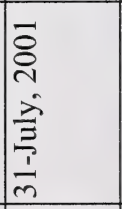 & 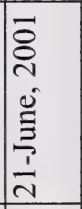 \\
\hline 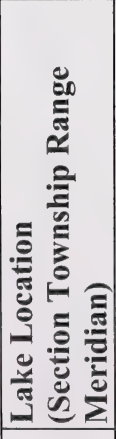 & 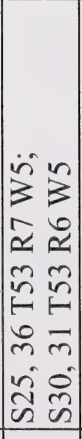 & 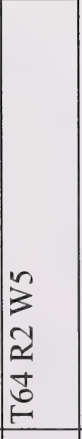 & 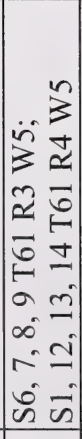 & 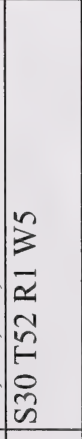 & 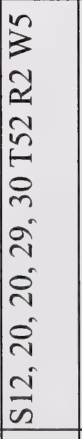 & 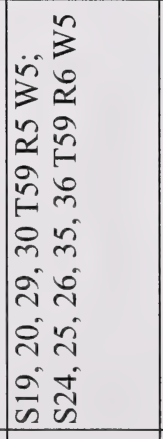 & 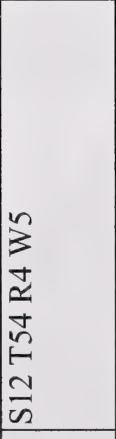 & 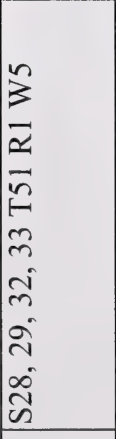 & 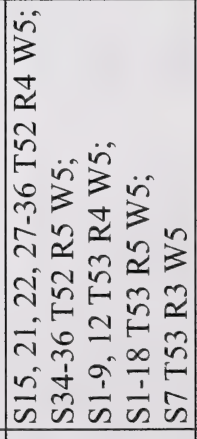 & 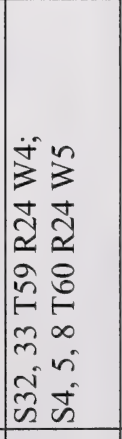 & $\begin{array}{l}n \\
3 \\
2 \\
2 \\
0 \\
1 \\
i\end{array}$ \\
\hline$\frac{\mathscr{y}}{\text { J }}$ & 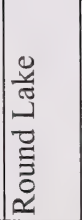 & 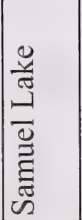 & 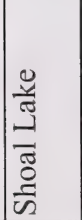 & 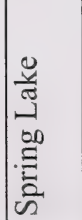 & 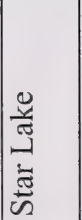 & 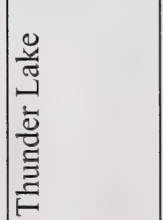 & 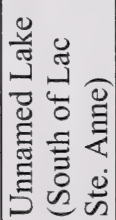 & 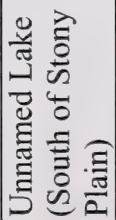 & 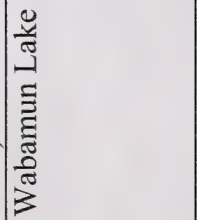 & 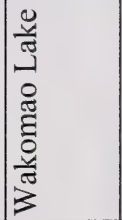 & 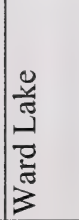 \\
\hline
\end{tabular}



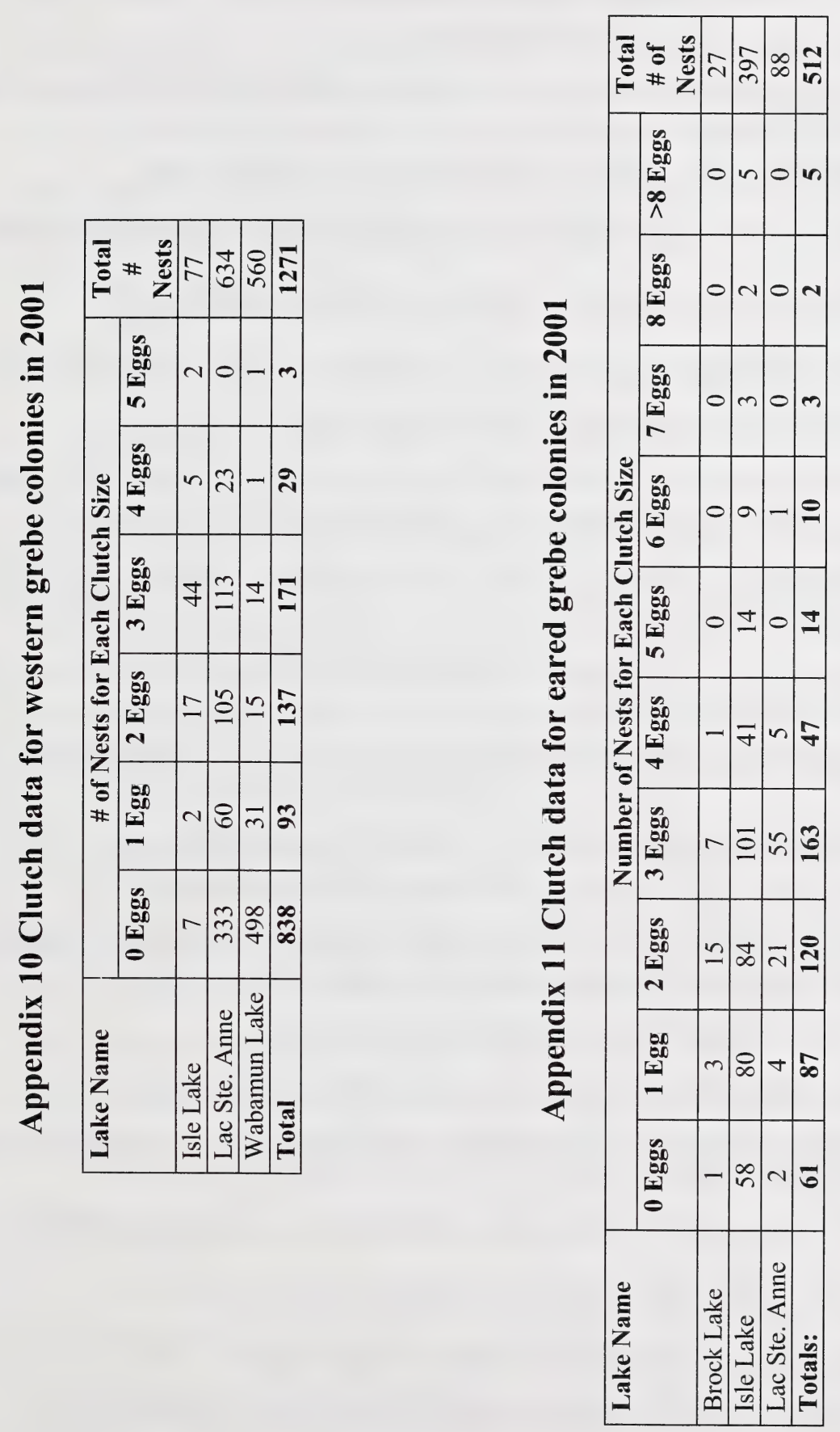


\section{List of Titles in This Series}

(as of February 2002)

No. 1 Alberta species at risk program and projects 2000-2001, by Alberta Sustainable Resource Development, Fish and Wildlife Division. (2001)

No. 2 Survey of the peregrine falcon (Falco peregrinus anatum) in Alberta, by R. Corrigan. (2001)

No. 3 Distribution and relative abundance of the shortjaw cisco (Coregonus zenithicus) in Alberta, by M. Steinhilber and L. Rhude. (2001)

No. 4 Survey of the bats of central and northwestern Alberta, by M.J. Vonhof and D. Hobson. (2001)

No. 52000 survey of the Trumpeter Swan (Cygnus buccinator) in Alberta, by M.L. James and A. James. (2001)

No. 6 2000/2001 Brassy Minnow inventory at Musreau Lake and outlet, by T. Ripley. (2001)

No. 7 Colonial nesting waterbird survey in the Northwest Boreal Region - 2000, by M. Hanneman and M. Heckbert. (2001)

No. 8 Burrowing owl trend block survey and monitoring - Brooks and Hanna areas, by D. Scobie and R. Russell. (2000)

No. 9 Survey of the Lake Sturgeon (Acipenser fulvescens) fishery on the South Saskatchewan River, Alberta (JuneSeptember, 2000), by L.A. Winkel. (2000)

No. 10 An evaluation of grizzly bear-human conflict in the Northwest Boreal Region of Alberta (1991-2000) and potential mitigation, by T. Augustyn. (2001)

No. 11 Harlequin duck monitoring in the Northern East Slopes of Alberta: 1998-2000 preliminary results, by J. Kneteman and A. Hubbs. (2000)

No. 12 Distribution of selected small mammals in Alberta, by L. Engley and M. Norton. (2001)

No. 13 Northern leopard frog reintroduction. Raven River - Year 2 (2000), by K. Kendell. (2001)

No. 14 Cumulative effects of watershed disturbances on fish communities in the Kakwa and Simonette watersheds. The Northern Watershed Project. Study 3 Progress report, by T. Thera and A. Wildeman. (2001)

No. 15 Harlequin duck research in Kananaskis Country in 2000, by C.M. Smith. (2001)

No. 16 Proposed monitoring plan for harlequin ducks in the Bow Region of Alberta, by C.M. Smith. (2001)

No. 17 Distribution and relative abundance of small mammals of the western plains of Alberta as determined from great horned owl pellets, by D. Schowalter. (2001)

No. 18 Western blue flag (Iris missouriensis) in Alberta: a census of naturally occurring populations for 2000, by R. Ernst. (2000)

No. 19 Assessing chick survival of sage grouse in Canada, by C.L. Aldridge. (2000)

No. 20 Harlequin duck surveys of the Oldman River Basin in 2000, by D. Paton. (2000)

No. 21 Proposed protocols for inventories of rare plants of the Grassland Natural Region, by C. Wallis. (2001)

No. 22 Utilization of airphoto interpretation to locate prairie rattlesnake (Crotalus viridis viridis) hibernacula in the South Saskatchewan River valley, by J. Nicholson and S. Rose. (2001) 
No. 23 2000/2001 Progress report on caribou research in west central Alberta, by T. Szkorupa. (2001)

No. 24 Census of swift fox (Vulpes velox) in Canada and Northern Montana: 2000-2001, by A. Moehrenschlager and C. Moehrenschlager. (2001)

No. 25 Population estimate and habitat associations of the long-billed curlew in Alberta, by E.J. Saunders. (2001)

No. 26 Aerial reconnaissance for piping plover habitat in east-central Alberta, May 2001, by D.R.C. Prescott. (2001)

No. 27 The 2001 international piping plover census in Alberta, by D.R.C. Prescott. (2001)

No. 28 Prairie rattlesnake (Crotalus viridis viridis) monitoring in Alberta - preliminary investigations (2000), by S.L. Rose (2001)

No. 29 A survey of short-horned lizard (Phrynosoma hernandesi hernandesi) populations in Alberta, by J. James (2001)

No. 30 Red-sided garter snake (Thamnophis sirtalis parietalis) education and relocation project - final report, by L. Takats (2002)

No. 31 Alberta furbearer harvest data analysis, by K.G. Poole and G. Mowat (2001)

No. 32 Measuring wolverine distribution and abundance in Alberta, by G. Mowat (2001)

No. 33 Woodland caribou (Rangifer tarandus caribou) habitat classification in northeastern Alberta using remote sensing, by G.A. Sanchez-Azofeifa and R. Bechtel (2001)

No. 34 Peregrine falcon surveys and monitoring in the Parkland Region of Alberta, 2001, by R. Corrigan (2002)

No. 35 Protocol for monitoring long-toed salamander (Ambystoma macrodactylum) populations in Alberta, by T. Pretzlaw, M. Huynh, L. Takats and L. Wilkinson (2002)

No. 36 Long-toed salamander (Ambystoma macrodactylum) monitoring study in Alberta: summary report 1998-2001, by M. Huynh, L. Takats and L. Wilkinson (2002)

No. 37 Mountain plover habitat and population surveys in Alberta, 2001, by C. Wershler and C. Wallis (2002)

No. 38 A census and recommendations for management for western blue flag (Iris missouriensis) in Alberta, by R. Ernst (2002)

No. 39 Columbian mountain amphibian surveys, 2001, by D. Paton (2002)

No. 40 Management and recovery strategies for the Lethbridge population of the prairie rattlesnake, by R. Ernst (2002)

No. 41 Western (Aechmophorus occidentalis) and eared (Podiceps nigricollis) grebes of central Alberta: inventory, survey techniques and management concerns, by S. Hanus, H. Wollis and L. Wilkinson (2002)

No. 42 Northern leopard frog reintroduction - year 3 (2001), by K. Kendell (2002)

No. 43 Survey protocol for the northern leopard frog, by K. Kendell (2002)

No. 44 Alberta inventory for the northern leopard frog (2000-2001), by K. Kendell (2002)

No. 45 Fish species at risk in the Milk and St. Mary drainages, by RL\&L Environmental Services Ltd. (2002) 



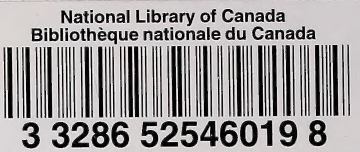

